106 IMPLEMENTATION OF THE LIVERPOOL CARE PATHWAY IN THE ACUTE SETTING IMPROVED END OF LIFE CARE

S Fullerton, ${ }^{1}$ Sandeep Bhagat ${ }^{1}$ Eastern Health, Victoria, Australia

10.1136/bmjspcare-2013-000491.106

Background The care of dying patients and families represents an important aspect of health service provision. 1500 patients a year die in Eastern Health beds, only $40 \%$ of whom are seen by the hospital based palliative care consultation team (HBPCCT). There is room to improve the quality of care offered to dying patients and families outside a specialist palliative care setting. The Liverpool Care Pathway (LCP) is an integrated, evidence-based, multidisciplinary document representing the 'Gold Standard' in quality end-oflife-care provision.

Aim To implement and evaluate the LCP in acute wards in $\mathrm{EH}$.

Methods Wards with the highest numbers of deaths were identified. After consultation, the LCP was implemented. Surveys of staff were carried out before and after implementation.

Results More than 200 patients and families have been cared for on the LCP. Some patients were discharged back to residential care and some to palliative care beds. Only $9 \%$ of the 88 surveyed staff who had used the LCP felt that it had not helped improve the care of dying patients and families in $\mathrm{EH}$, and $6 \%$ of staff felt that the LCP had not helped staff in caring for dying patients.

Conclusions Staff feel that the introduction of the LCP improved end of life care at EH. Use of LCP did not prevent transfer from acute beds to specialist palliative care beds.

\section{PILOTING AN INTEGRATED APPROACH OF ADVANCE CARE PLANNING FOR AN ELDERLY POPULATION WITHIN A PROVINCIAL CITY}

J Fowler ${ }^{1}$ Strategic Advisor for Elderly; Whanganui District Health Board; Wanganui, New Zealand

10.1136/bmjspcare-2013-000491.107

Background Advance Care Planning (ACP) has been introduced into New Zealand in recent years. New Zealand National ACP Cooperative has developed $\mathrm{ACP}$ tools and resources. Wanganui is a provincial region (population 62000 and above average elderly age group), and took the opportunity to take an integrated approach for piloting and implementing the Cooperatives tools.

Aim To implement ACP within Wanganui region and gain sector-wide engagement and coordination (integration).

Methods The 6 month pilot trialled the National ACP tools in primary and secondary areas; General
Practitioner practice; Maori patients in a medical ward; Assessment Treatment and Rehabilitation Service; Aged Residential Care Facility. Clinical staff in the pilot areas had ACP conversations with elderly participants. Clinical staff raised ACP awareness with the general public.

Results Of the 82 participants, $75 \%$ were interested in continuing ACP conversations (verbal and/or documented) with appropriate people for example, family/ whanau; health professionals; lawyers. The pilot evaluation and recommendations identified several key areas, including outcomes and challenges that are being addressed collaboratively across the sectors. These are forming the basis for a Wanganui district wide application of ACP, that are in align with national and regional directions.

Discussion An integrated approach has been a successful way to introduce ACP to Wanganui region stakeholders, and has enabled significant progress in a short period of time.

Conclusion Findings to-date, indicate the Wanganui pilot supports an integrated approach for ACP across the specialist; primary and community services, with a common vision, shared processes and systems to improve end of life health care for the elderly.

\section{DIGNITY OF LIFE AND PERSON-CENTRED PROCESSES FOR ADVANCE CARE PLANNING IN THE COMMUNITY}

C Smith, ${ }^{1}$ L Jaffray, ${ }^{2}$ I Ellis ${ }^{3}{ }^{1}$ Rural Clinical School University of Tasmania, Burnie, Tasmania, Australia; ${ }^{2}$ Rural Clinical School University of Tasmania, Burnie, Tasmania, Australia; ${ }^{3}$ School of Nursing \& Midwifery, University of Tasmania, Tasmania, Australia

10.1136/bmjspcare-2013-000491.108

Background As life expectancy increases, so do the number of elderly people living with advanced lifelimiting chronic illness, including prolonging life through artificial or mechanical means. The aim of Advance Care Plans is to ensure that individual's treatment wishes and preferences are known and respected.

Aim Whilst research continues in regard to the development of electronic Advance Care Plans in the palliative care setting and residential aged care setting, there is a need to understand the relevance and practicality of developing Advance Care Plans for use by elderly people living with life-limiting chronic illnesses in the community.

\section{Methods}

1. Systematic review-models of Advance Care Planning for elderly people living in the community

2. Meta- analysis and meta-synthesis

3. Interviews-sample of ACP programme stakeholders and community dwelling elderly (early 2013)

Results Seventy-one papers resulted from the search strategy with 17 papers selected for review. A meta-analysis and meta-synthesis has informed our 
proposed model for electronic Advance Care planning in the community-the Dignity of Life Model (a person-centred and dignity of life focussed approach). Interview data will inform the relevance and practicality of this proposed model.

Discussion This research will assist to understand the relevance and practicality of developing an electronic Advance Care Plan (eAPC) for use by elderly people living with life-limiting chronic illnesses in the community.

Conclusion Provide guidance on a model for electronic Advance Care Plan (eAPC) for use by elderly people living with life-limiting chronic illnesses in the community.

\section{TELEPHONIC ADVANCE CARE PLANNING FACILITATED BY HEALTH PLAN CASE MANAGERS}

I Boettcher, ${ }^{1}$ R Turner ${ }^{2}$ 'Spectrum Health, Michigan, USA; ${ }^{2}$ Priority Health, Michigan, USA

\subsection{6/bmjspcare-2013-000491.109}

Background Priority Health Case Managers (CMs) work telephonically with frail patients that have multiple co-morbidities. CMs have lacked facilitation skills for Advance Care Planning (ACP) discussions in this vulnerable population. Following a 6 -month pilot of telephonic ACP (TACP) in the Medicare population, TACP was implemented for the entire Medicare CM staff.

Aim To engage identified patients in First Steps $₫$ and Last Steps@ TACP.

Methods CMs were trained and certified by Respecting Choices $\odot$ to facilitate ACP discussions telephonically with both First Steps $\left({ }^{\circ}\right.$ and Last Steps $(\mathcal{C}$ protocols. CMs identified appropriate patients using hospitalisation and emergency room utilisation data, severity of illness and diagnostic criteria. The primary goal was to complete both the ACP discussion and document for each protocol on identified patients. CMs also attempted to schedule facilitated conversations with the health care advocate present.

Results In one calendar year, 155 patients were identified for TACP using established criteria. 59\% indicated they had an existing document identifying preferences for medical care. 35\% declined TACP. Last Steps $\odot$ discussions occurred in $15 \%$ of the patients. TACP resulted in eight new or updated documents.

Discussion Following TACP implementation to the Medicare CM team and evaluation of the results, processes and methods were instituted to increase engagement and completion of discussions and documents. These included enhancements to the electronic assessment and ongoing support of the CM team to increase engagement of patient and advocate.

Conclusion Dissemination of the project to the entire Medicare CM team demonstrates opportunities and lessons learned for facilitated TACP discussions.

\section{Morning Breakout 3-Aged Care}

110 PLACE OF DEATH AND END-OF-LIFE CARE IN NURSING HOME RESIDENTS AFTER IMPLEMENTING GERMANY'S FIRST REGIONAL ADVANCE CARE PLANNING PROGRAMME: A CONTROLLED TRIAL (STUDY PROTOCOL)

$\mathrm{J}$ in der Schmitten, ${ }^{1} \mathrm{~K}$ Wegscheider, ${ }^{2} \mathrm{G}$ Marckmann ${ }^{3}{ }^{1}$ Institute of General Practice, University Hospital, Düsseldorf, Germany; ${ }^{2}$ Institute for Medical Biometry and Epidemiology, University Hospital Eppendorf, Hamburg, Germany; ${ }^{3}$ Institute of Ethics, History and Theory of Medicine,

Ludwig-Maximilians-University, Munich, Germany

\subsection{6/bmjspcare-2013-000491.110}

Background Two years after implementation, a regional advance care planning (ACP) programme has led to a rate of meaningful and valid advance directives of $36 \%$ in nursing homes that adopted the programme (control: $0.4 \%$ ). Effects on clinical endpoints, however, were not compared yet.

Aim To evaluate whether a regional ACP programme leads to improved end-of-life outcomes, judged from the patients' perspective, and saves resources at the same time.

Methods Endpoints: Reduction of hospital days during the last 3 months of life (primary), increase of nursing home as place of death, improvement of quality of life during end-of-life period (as judged by bereaved relatives), and congruence of factual medical treatment in the last year of life with documented advance care plans.

Sample: All long-term care residents dying within 2 years study period PLUS all long-term residents deceased within 3 years before the study period in in the two post-intervention nursing homes, compared with a corresponding sample in two structurally similar control homes. 250 deceased residents per group are sufficient to demonstrate a reduction of the average number of hospital days from 5 to 3 days with a power of $80 \%$.

Analysis: Two-sided permutation tests for each endpoint, extended by statistical modelling.

Discussion Demonstrating relevant effects of regional ACP programmes on clinical outcomes is methodologically challenging, but possible and necessary. This study protocol has been proposed to the German ministry of education and research in 11/2012, the funding decision is pending.

\section{CPR POLICY AND PRACTICE IN AUSTRALIAN RESIDENTIAL AGED CARE FACILITIES (RACFS)}

M Sellars, ${ }^{1}$ W Silvester, ${ }^{1}$ R Fullam, ${ }^{1}$ R Sjanta, ${ }^{1}$ L Jackson, ${ }^{1}$ D Mawren, ${ }^{1}$ R Mountjoy ${ }^{1}{ }^{1}$ Respecting Patient Choices, Austin Health, Melbourne

\subsection{6/bmjspcare-2013-000491.111}

Background International literature suggests current Cardiopulmonary Resuscitation (CPR) policy and practice is highly variable and often ad-hoc in aged 
care settings. At present, there is no comparable published research on CPR policy and practice in Australian RACFs.

Aim To conduct a national survey on staff knowledge and attitudes, and policies and practices regarding CPR in Australian RACFs.

Methods An online survey was distributed to Australian RACF managers to examine the above.

Results Of 541 RACF managers, only 19\% agreed that CPR should be initiated in a witnessed cardiac arrest yet $83 \%$ reported that their facility would provide CPR. However, no CPR was administered in $75 \%$ of the facilities in the last 12 months and only once in $15 \%$. Only $63 \%$ of facilities had a CPR policy and, of these $44 \%$ believe that the policy is inadequate. $98 \%$ agreed that it is important to discuss resuscitation status with the resident or family, 96\% agreed that a resident CPR plan would help to reduce staff uncertainty and $82 \%$ supported the introduction of government CPR guidelines. $75 \%$ of respondents believed that survival rate of CPR in RACFs is $<10 \%$ and $35 \%$ (correctly) that survival is $<2 \%$.

Discussion CPR policy and practice is highly variable between RACFs in Australia, is inconsistent with the recognised outcomes and does not always reflect managerial attitudes and beliefs regarding CPR.

Conclusion The development of a national CPR guideline in Australian RACFs, and provision of education, will assist services in providing consistent and appropriate CPR practices to residents.

\section{THE PRACTICALITIES OF CROSS BOUNDARY WORKING IN RESPECT OF ACP FOR CARE HOME WITH NURSING RESIDENTS}

M Thorn, ${ }^{1}$ C Bloomer ${ }^{1}$ 'Marches Care Ltd, Shropshire, UK

\subsection{6/bmjspcare-2013-000491.112}

Background Within a care home with nursing reviewing the use of ACP to prevent inappropriate hospital admissions at end of life and the use of ACP to prevent delayed discharge from a General Hospital back to the care home.

Review of admission data from a care home to general hospital and on the number of admissions resulting in hospital deaths compared to care home deaths during the last 2 years.

Aim To highlight the importance of ACP, relationships with the hospital discharge team and community multi-disciplinary teams and how it successfully prevents inappropriate delayed discharges back to the care home setting.

Method We reviewed hospital admissions over the last 2 years, including who had an ACP, the interactions between the care home with the hospital, the length of hospital stay, and an audit of the feedback received from relatives and residents.
Also looking at more recent work providing 'step up' and 'step down' beds to support a local district general hospital and how having an ACP in place benefits patients.

Results This review is on-going (will be completed by end of March 2013) but early results suggest that where an ACP is in place the resident returns to the care home more quickly and both resident and family are more satisfied with the episode of care.

Discussion Challenges in the practicalities such as extracting information from different teams of professionals involved in the resident's care. The importance of building positive relationships with hospital wards and discharge teams.

Ensuring correct documentation re ACP goes into hospital with resident.

Conclusion The benefits of developing good cross boundary relationships with hospital teams and the importance of ACP helping prevent delayed discharges.

\section{THE KEY ELEMENTS TO SUSTAINING ADVANCE CARE PLANNING IN RESIDENTIAL AGED CARE TBC}

Rebekah Sjanta

10.1136/bmjspcare-2013-000491.113

\section{THE STATE OF PLAY: CURRENT ADVANCE CARE PLANNING (ACP) PRACTICE IN RESIDENTIAL AGED CARE IN ONE REGULAR AUSTRALIAN AREA HEALTH SERVICE}

J Dellit, ${ }^{1}$ K Shepherd, ${ }^{1}$ A Urban ${ }^{1}{ }^{1}$ Peninsula Health, Victoria, Australia

\subsection{6/bmjspcare-2013-000491.114}

Background Respecting Patient Choices (RPC) model of ACP has been established in Australia for 10 years. Peninsula Health has 35 residential aged care facilities (RACF) in its catchment area, yet few residents present to acute care with an ACP.

Aim To assess the current levels of ACP implementation including the degree of variation from the RPC model of evidence-based practice in the aged care sector.

Methods 30 participating RACFs underwent a comprehensive survey conducted via interview and a random 10\% sample health record audit to collect data. Data was collated and graphed across 30 domains of enquiry into ACP practice.

Results The survey revealed a state of broad variance in how ACP is implemented and practiced. Only 21\% indicated they routinely invite the resident to participate in ACP discussions. $20 \%$ of audited health records showed any evidence of the resident's involvement in ACP and only $41 \%$ had evidence of a substitute decision maker. Only $24 \%$ files evidenced recording of medical end of life care wishes (figure 1). 


\section{What evidence of ACP is found in the health record?}

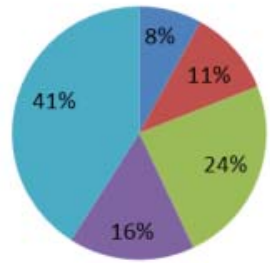

none

non-medical EOL

Medical EOL

aSDM
- Location of care

Figure 1

Discussion Significant gaps were identified in the nature and content of discussions undertaken and in the recorded level of involvement enabled from residents or their representatives.

Conclusion This study reveals that Aged Care Facilities need significant support to enable a transition to best practice in ACP.

\section{Morning Breakout 4-Community}

\section{THINK AHEAD: AN IRISH CARE PLANNING TOOL}

S Murphy, ${ }^{1}$ B O'Shea ${ }^{2}{ }^{1}$ Irish Hospice Foundation, Dublin, Ireland; ${ }^{2}$ School of General Practice, Trinity College Dublin, Dublin, Ireland

\subsection{6/bmjspcare-2013-000491.115}

Background Think Ahead is a public awareness initiative of the Forum on End of Life in Ireland. The Forum is guided by the National Council of the Forum on End of Life. An extensive year-long public consultation in 2009 identified a wide range of issues which impacted on end of life.

Aim To present the development of the Think Ahead project, an Irish public awareness initiative and system to guide people in discussing and recording their preferences.

Methods Resources, including a Think Ahead form and website (www.thinkahead.ie), have been developed. A wide range of consultation processes have been engaged in with members of the public as well as professional organisations and State agencies.

Results Two GP pilots were carried out, involving 120 patients up to 70 years of age, which looked at the people's experiences in filling in the Think Ahead form. Two regional community pilots were also conducted in 2012.

Discussion Think Ahead has been very positively received by the public and health professionals. The majority of people in all age groups considered Think Ahead to be a welcome initiative, in particular in its capacity to initiate conversations with family members who may be ill or dying. GPs reported that the tool had enhanced their relationship with their patients and reduced the potential for family conflict in relation to a person's wishes.
Conclusion The presentation will address the learnings of the public consultation and the pilots in relation to attitudes among the public to discussing preferences around end of life.

116 YOU DECIDES WHO DECIDES: AN ONLINE TOOL FOR CHOOSING ENDURING POWERS OF ATTORNEY

J Lawrence, ${ }^{1}$ H Rushford, ${ }^{2}$ J Chesterman, ${ }^{2}$ C McNamara, ${ }^{2}$

L Turnbull ${ }^{1}$ University of Melbourne, Victoria, Australia; ${ }^{2}$ Office of the Public

Advocate, Victoria, Australia

10.1136/bmjspcare-2013-000491.116

Background The Office of the Public Advocate's (OPA) experience of enduring powers of attorney indicates that the crucial step of thinking about who to appoint as substitute decision-maker and considering the sorts of decisions those people are likely to make, is too often overlooked in the haste to get the documents in place. OPA saw the need for resources that encourage people to consider these issues as an important part of the process.

Aim To develop an online, interactive facility, accessed through the OPA website, that guides participants to consider their important criteria when choosing substitute decision-makers.

Methods We established a collaborative partnership with Associate Professor Jeanette Lawrence, Psychological Sciences, University of Melbourne. A/ Professor Lawrence contributed psychological expertise on drawing out values and beliefs without bias and using stories as a vehicle to do this. She works with a team of graphics and programming experts who translate these ideas into computer programmes. A steering committee met regularly to develop the programme, which was subsequently trialled with 40 participants.

Results The programme was launched on the OPA website in October 2012. In addition, the programme has been produced in CD format to broaden accessibility. Discussion This tool assists in effective planning for the future through the appointment of appropriate representatives.

Conclusion Feedback indicates that the programme succeeds in getting people to think about criteria for whom to appoint as their representative and fills a resource gap.

\section{ACP FOR HEALTHY OLDER ADULTS: STRATEGIES AND TOOLS FOR A PUBLIC HEALTH APPROACH}

A Street, ${ }^{1} \mathrm{G}$ Threlkeld, ${ }^{1}$ J Blackford, ${ }^{1}$ B Bidstrup, ${ }^{1}$ J Downing ${ }^{1}{ }^{1}$ Faculty of Health Sciences, La Trobe University, Melbourne Australia

\subsection{6/bmjspcare-2013-000491.117}

Background Engaging older community-dwelling healthy adults in ACP discussions is an international public health challenge that requires social strategies to ensure uptake of ACP in non clinical settings. 
Aim The entrust-u study developed and tested an approach to ACP with older adults in rural communities that addressed guiding values, appointment of a decision maker, content of ACP discussions for healthy adults, documenting conversations and informing GPs.

Methods Collaborative action research was conducted over three cycles of planning, action, evaluation and reflection to develop and test the entrust-u process. We tested the use of life review, ecomaps and the 'Go Wish' game as strategies through interviews, focus groups and analysis of life reviews with 25 older people, 7 palliative care volunteers and four co-ordinators.

Results 25/25 older people completed a Future Wishes document, 18/25 appointed a substitute decision maker and 14/16 requested a follow up letter to their GP. All volunteers completed or re-visited their own MEPOAs and Future Wishes documents. We developed and refined a volunteer training module to be included in the Palliative Care Volunteers Kit that included a Train the Trainer process and a manual for coordinators of volunteers.

Discussion Discussions on preparation for death require a range of strategies and tools. We worked collaboratively with rural community palliative care services to initiate discussions on facing death and ACP through a three-stage flexible structured interview process.

Conclusion Entrust-u used a variety of tools and strategies to successfully involve palliative care volunteers in conducting ACP discussions with older people.

\section{ADVANCE CARE PLANNING IN A COMMUNITY SETTING FOR PEOPLE WITH CHRONIC DISEASE}

S Beedham, ${ }^{1}$ Mark Cockayne ${ }^{1}$ Silver Chain Group, Western Australia, Australia 10.1136/bmjspcare-2013-000491.118

Background The Silver Chain Group, one of Australia's largest primary health care providers, recognised that it is in a unique position to offer Advanced Care Planning (ACP) to large numbers of clients in their own home.

Aim The project aim was to develop a process and tools for the introduction of ACP within the community for people with chronic disease.

Methods Clients with chronic disease and receiving community nursing services were invited to participate. Specific tools and processes were developed. Registered Nurses (RNs) provided clients with information and referral to the project nurse. Clients were visited at home to facilitate ACP conversation, liaising with GPs, and assist with completion of documentation where required. Data including demographics and outcomes of interviews with clients and staff were collected and analysed.

Results Thirty-three clients were visited and engaged in advanced care planning; 12 completed advanced health directives. Seventeen clients engaged in end of life conversations with the $\mathrm{RN}$ and did not require further intervention. Interviews with clients demonstrated satisfaction with the outcome. Staff highlighted concerns with delivering the information relating to personal discomfort and professional capability. Tools and processes for community ACP were developed with recommendations for sustainable implementation.

Discussion The evaluation highlighted client and staff recommendations which include staff education and change management processes required to align culture and meet client needs.

Conclusion This project has been effective in highlighting the role of ACP within a large national primary health care organisation, and understanding the requirements of sustainable and systemic implementation.

\section{HEART AND SOUL: EFFECTIVE ADVANCE CARE PLANNING PROGRAMME PROVIDES INTERNATIONAL MODEL}

P Malley, ${ }^{1} \mathrm{M}$ Jane Markley, ${ }^{2} \mathrm{~L}$ Rastas ${ }^{3}{ }^{1}$ Aging with Dignity, Florida, USA; ${ }^{2} \mathrm{M}$. Jane Markley Consulting, LLC, Maryland, USA; ${ }^{3}$ Australian Pastoral Health Care Network, Melbourne, Australia

10.1136/bmjspcare-2013-000491.119

Background Aging with Dignity introduced the ACP tool Five Wishes in the USA in 1998 with a focus on personal care, family relationships, dignity, and spirituality. The concept is now helping to shape international efforts. Programme expansion includes Voicing My Choices: A Planning Guide for Adolescents and Young Adults, developed with the National Institutes of Health. Aim Describe a non-traditional, and replicable, approach to ACP that has proven effective and is positively influencing the development of ACP programmes internationally.

Methods Compilation of data on issues identified as 'most important' at the end-of-life, examination of an ACP resource that responds to these issues, review of data from recent NIH study of perceptions of ACP by adolescents and young adults, and an overview of the influence on international ACP efforts.

Results More than 19 million Five Wishes documents, available in 27 languages, are in circulation. More than 35000 partner organisations include hospitals, health systems, and places of worship. Known sites of replication efforts include Australia, China, Taiwan, Norway, and Italy.

Discussion Having a user-friendly and easy-tounderstand tool that encourages people to discuss their personal, emotional, and spiritual needs along with their medical wishes results in increased completion of usable and meaningful advance care plans.

Conclusion People respond well to ACP when matters of the heart and soul are included in the process, as well as when patients and families are 
empowered to make their own decisions. Lessons learned in this initiative provide helpful guidance for international efforts to encourage ACP.

\section{Afternoon Breakout 1-Mental Health}

\section{ADVANCE CARE PLANNING IN MENTAL HEALTH: LEGAL ISSUES AND NEW DEVELOPMENTS}

P Weller ${ }^{1}$ Centre for the Advancement of Law and Mental Health, Monash University, Melbourne

10.1136/bmjspcare-2013-000491.120

Background Advance Care Planning (ACP) in mental health raises a series of unique legal questions. Writing about 'advance statements' in Scotland, Jacqueline Atkinson identified them as the questions of nomenclature, capacity, content and legal status (Atkinson 2003). International comparisons of ACP in mental health shows that the broader human rights context in which mental health laws operate also influences the scope and interpretation of the key issues that underpin ACP practice.

Aim The aim this paper is to indentify prominent legal issues in ACP in mental health in Australia in light of the growing impact of the Convention on the Rights of Persons with Disabilities (CRPD).

Methods The analysis is based on the author's research as Post Doctoral Research Fellow and Deputy Director of the Centre for the Advancement of Law and Mental Health in the Faculty of Law at Monash University. This paper will discuss the four key issues by presenting an analysis on international and Australian jurisprudence with respect to the question of mandated housing and accommodation for people with mental health problems.

Discussion This approach highlights recent developments in the law, shedding light on the relationship between compulsory mental health laws and the common law. It illustrates the emerging recognition in law that the preferences of the person have significance in care and treatment decisions, highlighting areas of law and practice that remain uncertain.

Conclusion The paper argues that ACP practice in mental health will be facilitated by practical research into the law and its effects.

\section{AUSTRALIAN PSYCHIATRISTS' KNOWLEDGE, ATTITUDES, AND PRACTICE IN RELATION TO ADVANCE CARE PLANNING FOR MENTAL HEALTH TREATMENT}

R Mountjoy, ${ }^{1}$ W Silvester, ${ }_{1}^{1}$ R Newton, ${ }^{2}$ R Fullam, ${ }^{1}$ D Mawren ${ }^{1}{ }^{1}$ Respecting Patient Choices, Austin Health, Melbourne; ${ }^{2}$ Mental Health Clinical Services Unit, Austin Health, Melbourne

10.1136/bmjspcare-2013-000491.121

Background Proposed revisions to the Victorian Mental Health Act intend to consider Advance Care
Planning (ACP) in mental health treatment. No research has explored the feasibility and benefits of Psychiatric Advanced Directives (PADs) in Australia. International studies suggest that implementation of PADs can be limited by mental health clinicians' attitudes and knowledge.

Aim To establish Australian psychiatrists' knowledge, attitudes and practice regarding PADs.

Methods A national online survey of Australian psychiatrists.

Results Of 165 respondents, 56\% reported low to very low knowledge of PADs and only 27\% reported experience with PADs or a similar instrument. $76 \%$ of psychiatrists expressed support for the introduction of PAD legislation and $83 \%$ would be more inclined to use PADs if the law acknowledged their role as important. 79\% expected that PADs will have a positive impact on mental health care, with the benefits considered to outweigh specific clinical issues such as medication refusal (54\%) and limitations on patient care $(64 \%)$.

Discussion Australian psychiatrists have low levels of knowledge and experience regarding PADs. A high level of general support for PAD use and legislation was expressed.

Conclusion Australian psychiatrist expressed encouraging attitudes towards the implementation and use of PADs, and further research is required to develop an effective and sustainable model of ACP for mental health care in Australia.

\section{ADVANCE CARE PLANNING FOR MENTAL HEALTH TREATMENT: THE PERSPECTIVES OF AUSTRALIAN MENTAL HEALTH CLINICIANS}

D Mawren, ${ }^{1}$ W Silvester, ${ }^{1}$ R Newton, ${ }^{2}$ R Fullam, ${ }^{1}$ R Mountjoy ${ }^{1}$ Respecting Patient Choices, Austin Health, Melbourne; ${ }^{2}$ Mental Health Clinical Services Unit, Austin Health, Melbourne

\subsection{6/bmjspcare-2013-000491.122}

Background International research highlights that the successful implementation of Advance Care Planning (ACP) for mental health treatment can depend on clinicians' attitudes and knowledge of Psychiatric Advance Directives (PADs). With proposed revisions to the Victorian Mental Health Act considering the introduction of ACP, it is vital to explore the attitudes and knowledge of mental health clinicians in an Australian setting.

Aim To establish Australian mental health clinicians' knowledge and attitudes regarding PADs.

Methods A national online survey of Australian psychologists and case managers.

Results Of 260 respondents, $67 \%$ reported low to very low knowledge of PADs and only 20\% reported any experience with PADs. $73 \%$ of clinicians welcomed service change that would give consumers 
124 IS THERE AN IDEAL LEGAL FRAMEWORK FOR END OF LIFE DECISION-MAKING?

S Menon' ' Lien Centre for Palliative Care, Duke-NUS Graduate Medical School, Singapore

10.1136/bmjspcare-2013-000491.124

Background The law should help and not hinder patients, their loved ones and healthcare professionals in making advance care plans and end of life decisions.

Aim This paper will review the relevant laws of England and Singapore, and compare their frameworks for end of life decision-making.

Methods The advantages and disadvantages of each regime will be analysed in the context of three groups of patients and their loved ones facing an end of life scenario. The first group is patients who have capacity to make their own treatment decisions and have expressed their wishes. The second is patients who have lost capacity and did not make their wishes known, and the final group is patients who made their preferences known before they lost capacity.

Results There are some similarities between the English and Singapore frameworks but also some striking differences, especially relating to the powers of donees on healthcare decision-making and advance refusals of treatment.

Discussion Given initiatives in advance care planning in England and Singapore, this paper will make recommendations on the elements of an ideal legal framework. England and Singapore do not have legislation pertaining to Physician Orders for Life Sustaining Treatment (POLST) or default surrogates. Are these aspects essential in an ideal legal framework for end of life decision-making?

Conclusion The ideal legal framework is one that empowers patients and their loved ones to plan for their future health care and enables health care professionals to honour those wishes at the appropriate time. 
Aim The purpose of these classroom discussions was to ensure future Registered Nurses had a clear understanding of the limits of the WA ACP legislation in relation to their legal obligations as a registered health professional. Methods Qualitative methods were used including observation of class presentations, student interviews and opinions, written essays. Thematic analysis was applied to these data.

Results Themes included: the conflict between personal versus professional ethics; clear understand that WA ACP legislation covers what a person may refuse, but does not include mode of death; individual conflict about what the words 'beneficence' and 'nonmaleficence' really mean; the legal fact no-one has the right to self-determination about their death.

Discussion The Ethics and Law unit successfully challenges students' notions about patients' autonomous rights versus clinician obligation for non-maleficence and beneficence.

Conclusion Students demonstrate a depth of comprehension and compassion about WA ACP legislation, and significantly, how this may impact on their role as Registered Nurses in the future.

\section{Afternoon Breakout 3-Palliative Care}

\section{PAIN MANAGEMENT, END-OF-LIFE CARE AND DEMENTIA: ADDRESSING THE GAPS BETWEEN THEORY AND PRACTISE}

C Peisah, ${ }^{1,2}$ J Weaver $^{1}{ }^{1}$ Specialist Mental Health Services for Older People I Mental Health Drug and Alcohol, Northern Sydney Local Health District, Sydney Australia; ${ }^{2}$ School of Psychiatry, University of New South Wales, Sydney Australia

\subsection{6/bmjspcare-2013-000491.126}

Background Pain is frequently an undetected cause of agitation and distress in dementia; and thus often a cause of behavioural and psychological symptom of dementia (BPSD). Despite a plethora of tools specifically designed to assess pain in people with dementia, and empirical investigation of pain management protocols, successful pain assessment and management, and end of life care of people with cognitive impairment, particularly in residential care and inpatient facilities, still eludes us.

Methods We reviewed the current literature and surveyed staff of residential care and inpatient facilities within the Northern Sydney Local Health District regarding pain assessment and management, and end of life care in people with cognitive impairment.

Results We describe some of the barriers to the assessment of pain and end of life symptoms in people with cognitive impairment and identified practical solutions for facilitating assessment and management of these symptoms. We recommend a range of education strategies for addressing this issue.
Discussion There is a discordance between theoretical knowledge in the area of pain assessment and management and end of life care, and actual practice, which needs addressing.

Conclusion More extensive education and training about pain, end of life care and dementia is needed.

\section{LOW FOOD INTAKE IN OLDER PEOPLE WITH DEMENTIA}

S Rajaram, ${ }^{1}$ H C Chua' ${ }^{1}$ Nursing Department, Khoo Teck Puat Hospital, Singapore

10.1136/bmjspcare-2013-000491.127

Aim The aim of the study was to investigate the risk factors associated with older people in acute care setting for developing low food intake.

Background Eating difficulties among patients with dementia have been identified in Western countries and they progress when dementia advances. Previous studies have indicated that low food intake and weight loss is not a result of people with dementia not willing to eat independently.

Design The study consisted of nurses observing meal time observations. Observation was done for 3 days during lunch and dinner time.

Methods 17 participants were selected from patients with dementia from 2 geriatric units in an acute care hospital. Data was collected using the Barthel index, Mini Mental State Examination (MMSE) and Edinburgh Feeding Evaluation in Dementia (EdFED)

Results The prevalence of low food intake at meals in patients with dementia in the acute care unit was about $10 \%$. Eating difficulty, no feeding assistance, moderate dependence, few family visits, being female and older were six independent factors associated with low food intake.

Conclusion Nurses needed to assess the patients feeding ability to continue to self feed. To supervise the feeding of the patients with moderate dependency and appropriate verbal or physical assistance at meal times is recommended.

Relevance to clinical practice: Strategies to encourage families to visit their older relatives in acute care units is encouraged and recommended.

\section{DOES ADVANCE CARE PLANNING TRANSLATE INTO IMPROVED CARE IN A RURAL WESTERN AUSTRALIAN HOSPITAL SETTING?}

K Auret, ${ }^{1,2}$ C Sinclair, ${ }^{1}$ B Averill, ${ }^{1,3}$ S F Evans ${ }^{1}{ }^{1}$ Rural Clinical School of Western Australia, University of Western Australia, Western Australia, Australia; ${ }^{2}$ Albany Regional Hospital Palliative Care Service, Albany, Western Australia, Australia; ${ }^{3}$ Albany Community Hospice, Albany, Western Australia, Australia

\subsection{6/bmjspcare-2013-000491.128}

Background Western Australia (WA) passed legislation supporting formal advance care planning (ACP) in 
2010, allowing Advance Health Directive (AHD) and Enduring Power of Guardianship (EPG) forms. It is timely to audit the quality of end-of-life care provided in a rural area.

Aim Report ACP uptake and impact on end-of-life care in a rural hospital setting.

Methods This retrospective case notes-based audit of 90 admissions resulting in death was conducted in five rural hospitals in the Great Southern region of WA in 2012: the 100-bed regional centre $(\mathrm{N}=50)$ and four more remote $\sim 10$-bed facilities $(\mathrm{N}=10)$. A palliative care nurse used an in-house designed audit tool to collect data on demographics, process and outcomes measures. A palliative physician double coded five randomly selected sets of notes.

Results Most patients elderly ( $M=79.6$ years), admitted via ED (58\%), on average 13 days before death. Malignancy accounted for $40 \%$ of deaths. Some form of ACP was documented in 34\%, with $9 \%$ having an AHD and 1\% having an EPG. 50\% died on the Liverpool end-of-life care pathway, those on the pathway scored higher on a composite measure of care quality $\left(\chi^{2}(2,90)=31.6, p<0.001\right)$. ACP documentation did not predict likelihood of being commenced on the pathway $(p>0.05)$ or scores on the composite measure $(p>0.05)$.

Discussion As ACP is promoted in our community, our rural hospital network must develop system-wide responses to guarantee ACP influences care.

Conclusion This audit reports baseline data, which can be repeated following ACP-based interventions.

\section{Afternoon Breakout 4-Intensive Care}

\section{DIAGNOSING DYING: WHEN WE MISS THE BOAT}

Charlie Corke ${ }^{1}$ Barwon Health

\subsection{6/bmjspcare-2013-000491.129}

As good as Advance Care Planning (by both doctors and patients) may become we will still be confronted by the acutely deteriorating patient who will die without treatment -but might well have their death miserably prolonged by treatment. These decisions confront us on a daily basis.

Good medicine requires doctors to assist patients to make good decisions (a decision ie, right for that patient at that time).

This requires skills that are rarely taught but can be learned.

The decision making process in a high risk situation (death vs suffering) is complex.

The decision-making process requires two important components:

1. an understanding of the natural history of the disease that the patient has (without undue optimism)

2. an understanding of the person themselves (their values, wishes and fears).

Balancing the person (with their values, wishes and fears) with the medical situation that they find themselves in often reveals a clear treatment choice.
The thought process can help both the patient and the doctor arrive at a 'good' answer-and hopefully informs a shared decision.

The 'When Enough-is-Enough' course teaches this concept in a straightforward way that empowers junior doctors to explore their patient's values.

The concept is not new: In the early 1900s the great physician, Sir William Osler stated:

"It is much more important to know what sort of a patient has a disease than what sort of a disease a patient has."

His words are more pertinent today than ever.

\section{ADMISSION TO INTENSIVE CARE FOR PROVISION OF END OF LIFE CARE IN AUSTRALIA AND NEW ZEALAND: DO THE PATIENTS ALL DIE?}

A Melville, ${ }^{2}$ J Mitropoulos, ${ }^{1}$ S J Philpott, ${ }^{1,3}$ D V Pilcher ${ }^{1,2,3}{ }^{1}$ Department of Intensive Care, The Alfred Hospital, Victoria, Australia; ${ }^{2}$ Australian \& New Zealand Intensive Care Society (ANZICS) Centre for Outcome and Resource Evaluation; ${ }^{3}$ Department of Epidemiology and Preventive Medicine, Monash University, Victoria, Australia

\subsection{6/bmjspcare-2013-000491.130}

Background Caring for those at the end of their lives is an increasing component of work for Intensive Care Units (ICUs). Limited research is available about patients specifically admitted to ICU with the aim of providing end of life care.

Aim To define epidemiology of patients admitted to ICU for consideration of organ donation or palliative care and identify factors associated with outcome.

Methods Retrospective analysis of data from the Australian and New Zealand Intensive Care Society Adult Patient Database between 2007 and 2011.

Results Between 2007 and 2011, there were 1428 admissions to ICU for palliative care and 343 for consideration of organ donation $(0.4 \%$ of the total 445381 ICU admissions). Mortality was $87 \%$ and 93\% respectively, compared with $9 \%$ in patients admitted for active management. 122 patients were discharged home alive. Median length of ICU stay was $17 \mathrm{~h} \mathrm{(IQR} \mathrm{6-39)} \mathrm{in} \mathrm{the} \mathrm{palliative} \mathrm{care} \mathrm{group,} 24 \mathrm{~h}$ (IQR 14-42) in the potential organ donation group, compared with $42 \mathrm{~h}$ (IQR 22-86) in patients admitted for active management. The most common diagnosis was intra-cerebral haemorrhage. A diagnosis of gastrointestinal cancer (OR 12.3, 95\% CI 2.3 to $62.9, \mathrm{p}=0.002$ ) and planned admission following elective surgery (OR $4.3,95 \%$ CI 2.6 to 7.2 ), $\mathrm{p}<0.001$ ) were independently associated with being discharged home alive.

Discussion Admission to ICU for palliative care or consideration of organ donation is uncommon and most patients die. Functional status of survivors remains unknown.

Conclusion More work is required to better identify patients who might survive, and assess needs and functional outcomes. 
131 TALKING WITH FAMILIES ABOUT ORGAN DONATION IN THE ICU

R D Truog ${ }^{1}$ Harvard Medical School, Boston Children's Hospital, USA

10.1136/bmjspcare-2013-000491.131

Background There is a shortage of organs for lifesaving transplants, and organ donation is an altruistic act that should be supported and encouraged. Patients may indicate their desire to be an organ donor through donor registries, but in most countries transplant coordinators still seek the assent of the family before proceeding with donation. These conversations with families are ethically challenging.

Aim To explore the ethically challenging features of these conversations, in the context of talking with families about organ donation after circulatory death, or DCD.

Methods Review of the literature and of training videos that explore these ethical features.

Results Four ethical tensions are identified:

1. The decision to withdraw life sustaining treatment versus the decision to donate organs.

2. Optimising the quality of the dying process versus optimising the quality and quantity of the donated organs.

3. Obligations to provide balanced informed consent versus the belief that we should promote organ donation.

4. Belief that we need to follow the 'dead donor rule' versus increasingly contrived protocols for dying and definitions of death.

Discussion After exploring these four ethical features, we will view segments from a video training tape that illustrate different approaches for resolving these tensions.

Conclusion The important goal of promoting organ donation needs to be pursued with awareness and sensitivity for the ethical tensions inherent in this process.

\section{Plenary Session 6-Paediatrics \& Adolescents}

\section{PROGNOSIS-BASED GUIDELINES FOR TREATMENT LIMITATION DECISIONS IN NEWBORN INFANTS \\ D Wilkinson ${ }^{1}{ }^{1}$ University of Adelaide}

\subsection{6/bmjspcare-2013-000491.132}

Decisions to withdraw or withhold life-sustaining treatment from newborn infants are common in neonatal intensive care units (NICUs). The majority of deaths in NICU follow such treatment limitation decisions. There are professional guidelines for end of life decision-making in NICUs, however, these guidelines have been criticised. Many existing guidelines provide only vague guidance. For example, they indicate that treatment may be withheld when it is not in the best interests of an infant, but provide little assistance for clinicians in determining when this is the case. Other guidelines provide very specific criteria, for example specifying gestational age thresholds for resuscitation. However, guidelines of this nature potentially ignore other important prognostic factors.

In this talk I will examine the use of explicit prognosisbased guidelines for decision-making in intensive care. Is it possible and is it desirable to derive such guidelines? I outline and defend one potential practice framework based on the concept of 'gestational-age equivalence'.

\section{ADVANCE CARE PLANNING: A PARENT'S PERSPECTIVE}

TBC

10.1136/bmjspcare-2013-000491.133

No abstract

\section{MATURE MINORS AND REFUSAL OF MEDICAL TREATMENT}

C Tobin' ${ }^{1}$ Juris Doctor Student, University of Melbourne, Victoria, Australia

\subsection{6/bmjspcare-2013-000491.134}

Background In all Australian states, except South Australia, a minor is able to consent to treatment (provided he or she demonstrates a 'sufficient understanding and intelligence to enable him or her to understand fully' the proposed medical treatment ${ }^{\mathrm{i}}$ ) but not to refuse medical treatment. It has been argued that the law is inconsistent on this matter, that logic and consistency (as well as the modern understanding of the autonomy of the minor) would say that a minor who is sufficiently mature to consent to treatment should also be mature enough to refuse it, even if this causes the minor to die or suffer adverse consequences.

Aim An analysis of whether Australian law should allow a minor to refuse medical treatment.

Method The analysis of case law, legislation and academic opinion expressed in both legal and ethical journals.

Results As this is not an empirical study but a study of legal and ethical argument, the results are canvassed in the Discussion.

Discussion This paper canvasses the arguments for and against the recognition of such a right. It argues that the refusal of medical treatment is not merely the converse of the right to consent to medical treatment: refusal requires a higher level of maturity, in particular an appreciation of the long-term consequences of a decision to refuse treatment.

Conclusion This study concludes that Australian law should not recognise a right of the mature minor to refuse medical treatment.

'Gillick v West Norflock AHA (Gillick's case) [1986] AC 112 at 189 (HL); adopted into Australian law in Secretary, Department of Health and Community Services v JWB (Marion's Case) (1992) 106 ALR 385. 
135 FAMILY CENTERED ADVANCE CARE PLANNING FOR TEENS WITH CANCER (FACE-TC): 3-MONTHS OUT: ADVANCE DIRECTIVES, PSYCHOLOGICAL ADJUSTMENT, AND QUALITY OF LIFE

M E Lyon, ${ }^{1} \mathrm{~S}$ Jacobs, ${ }^{2}$ L Briggs, ${ }^{3}$ Y I Cheng, ${ }^{1}$ J Wang ${ }^{1}{ }^{1}$ Children's National Medical Center/Children's Research Institute/Center for Translational Science, Washington, DC, USA; ${ }^{2}$ Children's National Medical Center/Division of Oncology/Washington, DC, USA; ${ }^{3}$ Gundersen Lutheran Medical Foundation, Inc., La Crosse, Wisconsin, USA

10.1136/bmjspcare-2013-000491.135

Background Teens with cancer want to talk about their goals/values for end-of-life care. Yet, advance care planning rarely occurs for them.

Aim To pilot-test 3-month outcomes of the FACE-TC Advance Care Planning (ACP) intervention $(n=17$ dyads) versus Treatment As Usual (TAU) control ( $n=13$ dyads) regarding advance directives, psychological adjustment, and quality of life.

Methods A 2-group, randomised, controlled trial in hospital-based inpatient/outpatient oncology units clinics from 2009-2012 with teens with cancer aged 14 to 21 years and their family $(\mathrm{N}=30$ adolescent/family dyads). FACE-TC consist of three, weekly, 60 min sessions in a dyadic format with a trained/certified interviewer: (1) Lyon Advance Care Planning Survey@); (2) Respecting Choices Interview; (3) Five Wishes@.Three $60 \mathrm{~min}$ sessions were conducted 1 week apart. Three-month outcome measures were: advance directive; Beck Depression-II (BDI-II) and Anxiety Inventories (BAI); and Pediatric Quality of Life (Peds QL). Two teens did not complete follow-up (1 died, 1 host-graft disease), so 3-month analysis was with 28 dyads.

Results Adolescents' mean age was 16; 60\% male; 43\% Black. Advance directives documented in medical record at 3-month follow-up were $100 \%$ for intervention teens, $0 \%$ for controls (16 vs $0, p<0.0001)$. Measures of anxiety, depression and quality of life at 3-month follow-up did not significantly differ between FACE-TC and TAU groups for teens or their families, controlling for corresponding baseline measures.

Discussion/Conclusion The FACE-TC dyads completed ACP without harm. FACE-TC was not inferior to TAU. Three-month follow-up was too short and sample size too small to determine if FACE-TC was beneficial.

\section{Posters}

\section{IMPACT OF AN ADVANCE CARE PLANNING CLINIC ON PATIENTS OF A REGIONAL CARE COORDINATION SERVICE}

J Ironside, ${ }^{1}$ W Appleton, ${ }^{1}$ P Dugdale ${ }^{1,2}{ }^{1}$ Division of Medicine, Canberra Hospital and Health Services (CHHS); ${ }^{2}$ Centre for Health Stewardship, Australian National University

10.1136/bmjspcare-2013-000491.136

Background CHHS policy calls for staff to complete advance care plans (including a statement of choices) for patients with chronic disease. Numbers of completed plans are low, partly because some patients do not wish to complete one, and partly due to practical barriers to completion.

Aim To overcome practical barriers to completion of advance care plans.

Methods From April 2011 our Care Coordination Service established a fortnightly home- based Advance Care Planning Clinic, in which two staff visit patients at their home. In August 2012 this was supplemented by a fortnightly hospital-based clinic. Patients can be booked into either clinic. In the clinic, an Advance Care Plan is prepared comprising of a Statement of Choices and may include Enduring Power of Attorney, witnessed by an authorised clinic staff member. Partners are also offered the opportunity to complete their advance care plan at this time.

Results In January-March 2011, prior to the commencement of the clinic, there were 54 patients receiving care coordination of whom 19 (35\%) had a completed advance care plan, including a Statement of Choices. In October-December 2012 there were 89 patients who had received care coordination of whom 35 (39\%) had a completed advance care plan.

Conclusion The establishment of Advance Care Planning Clinics has been a practical way to help overcome multifactorial barriers to preparing a Statement of Choices, providing increased access opportunities and support for timely completion. This approach enabled staff to improve completion rates whilst managing a $65 \%$ caseload increase.

\section{FROM NFR TO AND: A POSITIVE APPROACH TO END} OF LIFE CARE DISCUSSIONS

J Frost, ${ }^{1} \mathrm{~K}$ Campbell ${ }^{1}{ }^{1}$ The Children's Hospital at Westmead, NSW, Australia

\subsection{6/bmjspcare-2013-000491.137}

Background We identified problems with paediatric end-of-life discussions, including language, content and location of documentation and information sharing with paramedics.

Aim To improve communication between clinical staff and between clinical staff and families about end of life care choices.

Methods We developed and implemented a novel approach: the Allow a Natural Death Policy and form. We collaborated with the NSW Ambulance Service to develop a system to communicate care choices to paramedics.

Results We audited the medical records of 43 children who died at CHW January-September, 2011. The results were:

- $15(35 \%)$ did not have any information about end of life care choices

- 28 (65\%) had end of life care choices documented 
Where no End of Life Care choices were documented:

- $10(66 \%)$ were Coroners cases

- $8(53 \%)$ had an admission of $\leq 1$ day

- $8(53 \%)$ died in PICU

- $6(40 \%)$ died in Emergency Department

- $1(7 \%)$ died in an inpatient ward

Compliance with completing the AND was high, with the following sections completed 100\%:

- Patient ID sticker

- FACS information

- Interpreter information

- Goals of care

- Response section

- Standing order section

- Medical Officer details

Paramedic data is yet to be audited.

Discussion This project was well received by clinicians, paramedics and families. The audit demonstrated successful implementation.

Conclusion Focussing on the positive choices for care, rather than the withdrawal of care, has made difficult discussions easier and junior staff clear guidelines.

\section{COMFORT CARE FOR A HEPATOCELLULAR CARCINOMA PATIENT IN HOSPICE WARD}

Y Chen, ${ }^{1}$ S-F Cheng ${ }^{1}$ Changhua Christian Hospital, Taiwan, China

10.1136/bmjspcare-2013-000491.138

Background Cancer is the major cause of illness and mortality in Taiwan. It is noteworthy that the psychosocial and spiritual needs of patients with terminal cancer patients often are neglected by families and healthcare providers in Taiwan.

Aim The purpose of this study was to apply the Comfort Theory to explore the experience on comfort care of a patient with terminal HCC near the end of life in hospice ward.

Methods Data were collected and evaluated based on Kolcaba's theory of comfort. It directs nurses to assess physical, psycho-spiritual, sociocultural and environmental comfort needs of the patient; design holistic interventions to meet those needs; and measure the effectiveness of interventions to enhance the patient's comfort.

Results Four contexts of a terminal hepatocellular carcinoma patient experience are as follows: (a) Physical: abdominal distention resulted from ascites deterioration. (b) Psycho-spiritual: Fear of death anxiety resulted from the uncertainty of life-threatening. (c) Sociocultural: Altered family process resulted from family worry and conceals the patient's condition. (d) Environmental: Un-homelike setting related to the limitation of hospital hardware.
Discuss The caring experience of this study provide important information to health professionals while caring terminal cancer patients based on their comfort needs. Health professionals could design an individualised care plan, establish a trusting relationship, control symptoms, provide complementary medicine, reconnect family relationship and create a homelike atmosphere to meet patients' needs.

Conclusion The study will help health professionals to perceive psychosocial and spiritual needs and properly provide support for terminal cancer patients.

\section{ADVANCE CARE PLANNING AS A DYNAMIC PROCESS: A DESCRIPTIVE 1 YEAR REVIEW OF CHANGES IN ACP PLANS IN TAN TOCK SENG HOSPITAL}

$\mathrm{R} \mathrm{Ng},{ }^{1} \mathrm{R}$ Chong, ${ }^{2} \mathrm{H} \mathrm{Chau},{ }^{2} \mathrm{C} \mathrm{H} \mathrm{Poi},{ }^{1}$ J Eng Ramdat, ${ }^{1}$ Y Z May, ${ }^{2}$ A Loke, ${ }^{2}$ H Y Wu ${ }^{1}{ }^{1}$ Tan Tock Seng Hospital, Palliative Medicine; ${ }^{2}$ Tan Tock Seng Hospital, Operations Community, Singapore

\subsection{6/bmjspcare-2013-000491.139}

Background Advance care planning (ACP) is a process and people can change their minds about treatment preferences when goals of care change. The ACP project team in Tan Tock Seng Hospital continually audits ACP outcomes including any change in ACP plans.

Aim To examine rate of change in ACP plans and factors that may have contributed to changes in ACP plans.

Methods ACP outcomes for readmissions and death were analysed from retrospective audit of paper and electronic medical records.

Results Between October 2011 to December 2012, a total of 154 Preferred Plan of Care (PPC), a POLST-type ACP were completed with patients and/ or their next-of-kin (NOK). Out of these 154 PPCs, 5 ACP plans were revised. Time lapse between creation of first and second ACP plan ranged from 3 to 91 days. One patient had decision making capacity at first and second ACP documentation, while 4 other patients had no decision making capacity at both ACP documentation. four revisions were initiated by doctors whilst one was initiated by the substitute decision maker. Two ACP plans were changed after further clarifications with NOK whilst three revisions took place when there were changes in the patients' medical condition or after trial of medical intervention. Three of the patients have since passed away.

Discussion The number of changed ACP plans is a small fraction of the total completed. Doctors were active in continual exploration of ACP plans.

Conclusion In our cohort, ACP plans remain relatively stable. ACP is a dynamic process that need a culture of review and re-exploration of care preferences in order to be responsive to changes in medical condition and care preferences. 
140 PERCEPTIONS OF BENEFITS AND BARRIERS IN CONDUCTING ADVANCE CARE PLANNING: A CROSS-SECTIONAL SURVEY OF TRAINED ADVANCE CARE PLANNING FACILITATORS

$\mathrm{R} \mathrm{Ng},{ }^{1} \mathrm{R}$ Chong ${ }^{2}{ }^{1}$ Department of Palliative Medicine, 20perations Community. Tan Tock Seng Hospital, Singapore; ${ }^{2}$ Tan Tock Seng Hospital, Operations Community, Singapore

\subsection{6/bmjspcare-2013-000491.140}

Background Since 2010, within Tan Tock Seng Hospital (TTSH), pilot projects in advance care planning (ACP) were initiated with patients with chronic disease, organ failure and advanced illnesses such as terminal cancer.

Aim To evaluate the attitudes and perceptions of trained ACP facilitators in TTSH.

Method An anonymous cross-sectional survey in the form of a questionnaire was administered to all certified ACP facilitators in the hospital.

Results A total of 59 trained facilitators, comprising nurses (36\%), doctors (29\%), medical social workers $(25 \%)$ and case managers $(8 \%)$ responded to the survey. Majority (95\%) of respondents favour ACP and $86 \%$ consider ACP as one of their roles. More than $90 \%$ respondents felt that ACP promotes patientcentred care, improves communication, and reduces burden of decision making on families. Most of the time (53\%), initiation of ACP was by doctors.

90\% respondents felt that ACP is challenging to conduct. Major barriers to conducting ACP are lack of time $(66 \%)$, perception of low receptivity to ACP in patients' families (53\%), patients' lack of understanding of ACP (50\%) as well as language barriers (48\%).

Discussion While the attitudes of trained facilitators towards ACP are largely positive, there are significant barriers to ACP facilitation, namely a lack of time.

Conclusion Whilst it helps to spread advocacy for and practice of ACP in training facilitators from multiple healthcare disciplines, there is also a need for careful consideration of resource allocation such as dedicated ACP facilitators, for successful implementation of ACP.

\section{STARTING PILOTS IN ADVANCE CARE PLANNING IN A TERTIARY HOSPITAL IN SINGAPORE: 1 YEAR REVIEW}

$\mathrm{R} \mathrm{Ng},{ }^{1} \mathrm{R}$ Chong, ${ }^{2} \mathrm{H} \mathrm{Chau},{ }^{2} \mathrm{C} \mathrm{H} \mathrm{Poi,}{ }^{1}$ J Eng Ramdat, ${ }^{1} \mathrm{Y} \mathrm{Z} \mathrm{May,}{ }^{2}$ A Loke, ${ }^{2} \mathrm{H}$ Y Wu ${ }^{1}$ Tan Tock Seng Hospital, Palliative Medicine; ${ }^{2}$ Tan Tock Seng Hospital, Operations Community, Singapore

\subsection{6/bmjspcare-2013-000491.141}

Background Engagement with Respecting Choices since 2009 resulted in pilot initiatives in advance care planning (ACP) starting in hospitals and the community in Singapore since 2009. Since December 2011, a dedicated ACP project team was formed in Tan Tock Seng Hospital to support ACP pilot initiatives. These initiatives namely Preferred Plans of Care (POLST-type ACP) sprouted in the disciplines of Cardiology, Neurology, Neuro-surgery, General Medicine, Palliative Medicine, Post Acute Care at Home, Respiratory Medicine and Home Ventilation and Respiratory Support Services.

Aim To audit awareness of ACP plans and congruence of patients' ACP plans with care delivery during readmission episodes and upon death.

Methods ACP outcomes for readmissions and death were analysed from retrospective audit of paper and electronic medical records.

Results From October 2011 to December 2012, a total of 154 preferred plans of care were completed with patients and/or next-of-kin. Five ACP plans were revised. Medical team was aware of patients' ACP plans in $75 \%$ of 67 readmissions. Medical interventions and initial place of care in event of deterioration were congruent with patients' stated preferences in $98 \%$ and $94 \%$ of readmissions respectively. Preferred place of death was honoured $74 \%$ upon death of patients.

Discussion There was high awareness of advance care plan during readmission, and high congruence between patients' preferences and care delivery.

Conclusion Advance care planning is an effective process in honouring patients' care preferences. More can be done to examine resource allocation, sustainability and reach of the programme and to address barriers to ACP.

\section{SPECIALIST PALLIATIVE CARE SERVICE RESPONSIBILITY TO SUPPORT PRIMARY CARE PROVIDERS IN CARE PLANNING AND END OF LIFE CARE: A REVIEW \\ M Cole ${ }^{1}$ Community Palliative Care Service, Castlemaine Health, Victoria, Australia \\ 10.1136/bmjspcare-2013-000491.142}

Background Following a gradual but consistent increase in requests from within Castlemaine Health, a review of service provision by the Community Palliative Care Service (CPCS) was undertaken to determine a sustainable level of support to Primary Care Services.

Aim Although this is a small rural service, the CPCS should provide support to primary care services during an episode of a person's care. This includes promotion of a palliative approach across all care settings and to the community in general.

Methods Data for the previous 2 years was reviewed to identify episodes of shared care or consultation to primary care providers; Key stakeholders interviewed and responses grouped into themes of need/support; Education provided and evaluated; Stakeholder review to determine perceived benefit.

Results The number of shared care or 'consultation' episodes was not reflected in the data due to limited 
reporting fields and inconsistency of data entry. Stakeholders agreed that palliative care occurs across all settings but recognition by primary care staff continues to be low. There was a perceived need to increase staff confidence in abilities, recognising transition of care (phases) and reviewing Advance Care Plans. Two education programmes were provided with 47 staff attending. On 10 point scale there was a shift of $+2 /+2.2$ respectively in knowledge of after education.

Discussion Access to Palliative Care Staff on a regular basis increases staff confidence within Primary Care Services.

Conclusion Increased support and direct promotion of the Palliative Care Service is beneficial for assessment and care planning across Primary Care Services.

\section{AN AUDIT OF THE PREVALENCE AND CHARACTERISTICS OF ADVANCE CARE PLANNING FOR PATIENTS FROM RESIDENTIAL AGED CARE FACILITIES (RACFS) REFERRED TO THE MOBILE ASSESSMENT AND TREATMENT SERVICE (MATS)}

B Jafari, ${ }^{1}$ N Austin, ${ }^{2}$ R Lemke, ${ }^{1} S$ Poojary ${ }^{1}$ Department of Aged Care, Caulfield Hospital, Alfred Health, Victoria, Australia; ${ }^{2}$ Clinical innovation and interdisciplinary projects, Caulfield Hospital, Alfred Health, Victoria, Australia

\subsection{6/bmispcare-2013-000491.143}

Background Advance Care Planning (ACP) ensures recognition of a person's wishes and promotes autonomy, however, completion and implementation has been a challenge.

Aim To assess the prevalence of ACP in patients from Residential Aged Care Facilities (RACFs) referred to the 'Residential In-reach' service of Alfred Health known as Mobile Assessment and Treatment Service (MATS), and to assess how the process of ACP has been approached by the mangers of those facilities.

Methods Part A: Prospective audit of documentation of ACP for 100 patients referred to MATS

Part B: De-identified, paper-based surveys of the managers of the RACFs where the patients from part A of the study were residing.

Results Part A: The prevalence of ACP, Medical Enduring Power Of Attorney and 'Not for Resuscitation' form were 38\%, 37\% and 35\%, respectively. Patients with ACP or a separate 'NFR' form were significantly more likely to be living in high care compared to low care facilities $(79 \%$ vs $21 \%, \mathrm{p}=0.049$ and $80 \%$ vs $20 \%, \mathrm{p}=0.032$, respectively).

Part B: There was a significant inconsistency between the facilities with regards to 'facility requirements' for ACP, 'person responsible', 'documentation' and 'GP involvement'.

Discussion This study found a low prevalence of ACP, MEPOA and 'NFR' form in patients from RACFs referred to MATS. There was also lack of a systematic approach in the process of ACP.
Conclusion There is a need for structured policy coupled with appropriate funding as well as further education of both public and health professionals.

\section{COMMUNICATION AND COORDINATION DURING TRANSITION OF OLDER PERSONS BETWEEN NURSING HOMES AND HOSPITAL STILL IN NEED OF IMPROVEMENT}

M Kirsebom' ${ }^{1}$ Uppsala University

\subsection{6/bmjspcare-2013-000491.144}

Background It has previously been reported that transfers to hospital from nursing homes and discharge of patients from hospital are surrounded by communication difficulties. However, studies focusing on both hospital and nursing home registered nurses' experiences of communication and coordination within and between nursing homes and hospitals are uncommon.

Aim To investigate registered hospital and nursing home nurses' experiences of coordination and communication within and between care settings when older persons are transferred from nursing homes to hospital and vice versa.

Methods In 2008, three focus group discussions were conducted with registered nurses from hospitals and nursing homes $(n=20)$. Data were analysed using content analysis.

Results Nursing home registered nurses found it difficult to decide whether or not the older person should be referred to hospital from the nursing home. Hospital registered nurses reported often trying to stop premature discharges or having to carry out the discharge although it had not been fully prepared. Both hospital and nursing home registered nurses suggested increased collaboration to understand each otheŕs work situation better.

Conclusion Communication and coordination among hospital and nursing home registered nurses need to be furthered improved. Registered nurses' coordination and planning in the nursing home are extremely important to future elder care. We recommend that the medical care plan be regularly updated and meticulously followed, the aim being to reduce the risk of inappropriate medical treatment and nursing care as well as unnecessary transfer and admission to hospital.

\section{ETHICAL ISSUES FOR JAPANESE NURSES IN END-OF-LIFE CARE: FROM ANALYSIS OF THE ANGUISH OF NURSES IN AN ACUTE WARD}

M Kiyama, ${ }^{1}$ N Morishita, ${ }^{2}$ H Tajima ${ }^{3}{ }^{1}$ Faculty of Health Promotion Sciences, Hamamatsu University; ${ }^{2}$ Department of Integrated Human Sciences, Hamamatsu University School of Medicine; ${ }^{3}$ Faculty of English and IT Management, Shumei University

\subsection{6/bmjspcare-2013-000491.145}

Background In Japan, many clinical nurses experience ethical dilemmas in daily nursing practice that 
cannot be resolved easily. Nurses feel strong regret in particular in cases in which the patient is at the end of life. Accordingly, based on one end-of-life case we elucidated the aspects of the patient's condition and the thoughts and disorientation of the nurses.

Aim To consider ethical issues for clinical nurses in end-of-life care.

Methods We surveyed seven nurses on the nursing team involved in this case, through group interviews. The interviews concerned topics including nursing policies and plans, the content of conferences, and the dilemmas nurses experienced.

Results Through data analysis, we identified 63 codes, 25 subcategories, and six core categories. While admitted, the patient constantly used the nursecall for various reasons. She made particularly many calls during the postoperative acute stage and the postoperative recovery stage. In the postoperative acute stage, the nurses anticipated a danger when hearing the nurse-call, immediately answered the call, and went to her room to take appropriate action. However, during the postoperative recovery stage, the nurses were not aware of her sense of anxiety and were confused by the patient's frequent nurse-calls, even during recovery.

Discussion Gaps developed between the patient's thoughts and the ethical assumptions of nurses in end-of-life care. This gap was due to differences in each other's goals.

Conclusion This study will support promotion, from the nurse's point of view, of the provision of medical care that satisfies patients, which has not advanced smoothly in Japan.

\section{PATIENTS' RIGHTS IN INTENSIVE CARE UNITS}

E Kleanthous ${ }^{1}{ }^{1}$ Cyprus University of Technology, Limassol, Cyprus

10.1136/bmjspcare-2013-000491.146

Background The principle of patient autonomy is important in all European laws about Patients Rights. However, little research has been done investigating healthcare providers, relatives and patients' knowledge and attitudes regarding patients' rights. As far, almost none has been done investigating patients rights in intensive care units.

Aim A review of literature will be presented regarding knowledge and attitudes of healthcare providers, relatives and patients regarding patients' rights in intensive care units and especially the principle of autonomy in decision making process.

Methods For this review CINAHL, Pubmed and Medline were searched under the keywords 'patient rights', 'critically ill' and 'autonomy', 'decisionmaking'.
Results Patient rights have been included in the research findings as a main issue in intensive care units among other important issues, such as decisionmaking, privacy and end of life care. Health care professionals must understand patients' and families' wishes and increase the communication in the intensive care units in order to provide patient autonomy and privacy.

Discussion It was evident from the literature review that critically ill patients cannot actively participate in decisions about their health and treatment, but the health care professionals and families must respect them as human beings. Patient rights are fundamental for all the people in the hospitals.

Conclusion Further research is needed to determine the extent to which patients' rights are respected in intensive care units and in addition to examine the knowledge and attitudes of health care professionals and relatives regarding patients' rights of critically ill patients

\section{HOME AS THE PREFERRED PLACE OF DEATH: ARE THERE LIMITATIONS?}

S Ganga-Krishnan, ${ }^{1}$ Lawrence Wong, ${ }^{1}$ Angeline Song, ${ }^{1}$ Tan Hui Nah, ${ }^{1}$ Irwin Chung ${ }^{1}{ }^{1}$ Agency for Integrated Care, Singapore

10.1136/bmjspcare-2013-000491.147

Background The HOME Programme provides home palliative services to patients with end-stage organ failure in Singapore.

Aim To study the reasons for patients who were not able to fulfil their wish to die at home.

Method A retrospective study was done based on historical data gathered from case notes of patients who had died during the period of April 2011 to September 2012.

Results A total of 143 patients had died. 102 patients (71\%) had completed their ACP. Out of the 102 patients, $62(61 \%)$ chose their homes as their preferred place of death.

Out of the 62 patients who had chosen their homes as their preferred place of death, 41 patients (71\%) died at home while 21 patients (29\%) did not have their wish fulfilled.

\section{Discussion}

Conclusion Singapore has a multi-ethnic population. It's diverse cultural beliefs and perspectives towards palliative care and care-giving have an impact on end of life care decision-making.

Currently, there is little research in this area. This paper has identified some causes to why patients were not able to fulfil their wish to die at home. It also navigates the way for future research to help patients die at home according to their wishes. 


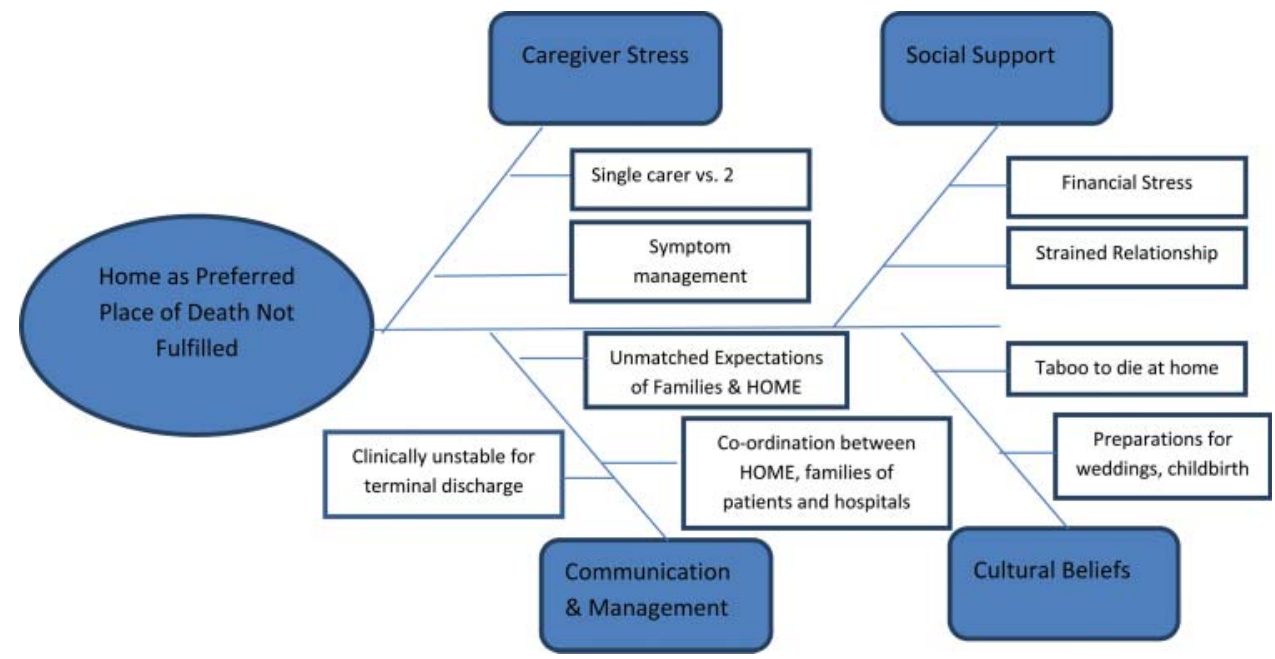

Figure 1 Cause and Effect Diagram

148 INFORMED CONSENT IN ADVANCE CARE PLANNING IN THE PALLIATIVE CARE SETTING: A DECISION AID LIBRARY FOR END OF LIFE CARE

T Krones, ${ }^{1,2}$ B Loupatatzis, ${ }^{1}$ B Steffen-Bürgli, ${ }^{1}$ D Otto, ${ }^{1}$ M Brunner, ${ }^{1}$ N Biller-Andorno, ${ }^{2} \mathrm{G}$ Eisele, ${ }_{1}^{1} \mathrm{~J}$ in der Schmitten, ${ }^{3} \mathrm{C}$ Mitchell, ${ }_{1}^{4} \mathrm{~S}$ Obrist, ${ }^{2}$ D Poster, ${ }^{1}$ T Rordorf, ${ }^{1} \mathrm{~K}$ Schad, ${ }^{1} \mathrm{R}$ Spirig, ${ }^{2}$ A Volandes, ${ }^{4} \mathrm{~K}$ Zaugg, L Zimmerli' ${ }^{1}$ University Hospital Zurich, Switzerland; ' ${ }^{2}$ University of Zurich, Switzerland; ${ }^{3}$ University of Dusseldorf, Germany; ${ }^{4}$ Harvard Medical School, Boston, USA

\subsection{6/bmjspcare-2013-000491.148}

Background Advance care planning has been discussed from a variety of perspectives. It aims to support a patient-centred process in which patients, together with their loved ones and their caregivers, are enabled to make informed decisions regarding future health care events. Although both accurate information about prospective health care problems and alternatives and help with personal decision making by advance care planning facilitators are crucial, the information given to patients in an ACP process is mostly rough, short, and left to physicians and thus does not fulfil the criteria of an 'evidence based patient choice' nor even of general standards for "informed consent"

Aim To construct an evidence based paper and videobased Decision Aid Library for End of Life Care for best patient information supporting the ACP facilitation process

Methods We screened the literature for evidencebased information and evidence-based decision aids regarding (1) general Goals of Care, (2) Resuscitation (3) Tube Feeding (4) Antibiotics, (5) Ventilation (6) Dialysis Withdrawal and (7) last place of Care and constructed a library of evidence-based decision aids, qualitatively pretested by staff and patients.

Results Following a methodical screening process, a library of evidence-based papers and videos was constructed, which is currently being qualitatively evaluated by staff and patients as the first step in a grant-funded randomised controlled trial on the effect on ACP for palliative care patients in Switzerland.

Discussion We will discuss the content and qualitative results of the Decision Aid Library at the Melbourne Conference

Conclusion From an ethical point of view, best information is crucial for making informed choices. If the decision aid library proves to be useful, evidencebased information and decisions aids should become part of ACP programmes.

\section{ADVANCE CARE PLANNING AND PALLIATIVE CARE IN CHRONIC DISEASE SYMPTOM MANAGEMENT}

N Kubokawa, ${ }^{1}$ M Nishikawa, ${ }^{1}$ Y Yokoe, ${ }^{1}$ K Fukuda, ${ }^{1}$ H Hattori, ${ }^{1}$ H Yong-Jae, ${ }^{1}$ H Miura, ${ }^{1} \mathrm{H}$ Endo, ${ }^{1} \mathrm{~K}$ Nakashima ${ }^{2}{ }^{1}$ National Center for Geriatrics and Gerontology, Japan; ${ }^{2}$ Pallium Hospice, Japan

\subsection{6/bmjspcare-2013-000491.149}

Background Opioids are important in symptom management of dyspnoea in chronic diseases, for example, chronic obstructive pulmonary disease (COPD). Existing literature indicates that in the absence of advance care planning (ACP) for end-of-life decisions, we should consider whether concomitant opioid use is appropriate. In Japan, the appropriate timing of ACP for dyspnoea symptom management in chronic diseases is poorly understood.

Aim The primary aim was to clarify whether ACP should be performed by the palliative care (PC) team concomitantly with morphine administration. The secondary aim was to clarify the opinion of home care support physicians on concomitant use of opioids and ACP.

Methods We investigated the level of ACP conducted by PC teams among patients who were using opioids. We conducted an inventory survey on the concomitant 
use of morphine and ACP among 220 doctors, including 147 home care support physicians.

Results ACP was conducted by PC teams for all patients who were using opioids. PC team members agreed to concomitantly perform ACP and opioid administration for dyspnoea in diseases such as COPD, 137 (62.3\%) among 220 doctors, including 147 home care support physicians were agreed to.

Discussion In comparison with PC team members, the ratio of home care support physicians who advocated ACP concomitantly with morphine for dyspnoea was low.

Conclusion This study clarified the opinions of home care support physicians and PC team members on the concomitant use of opioids and ACP.

\section{SURVEY OF THE ATTITUDES OF GENERAL PRACTITIONERS AND PATIENTS ABOUT DISCUSSING RESUSCITATION}

I Lim, ${ }^{1}$ W Silvester ${ }^{2}$ Creswick Medical Centre, Creswick, Victoria; ${ }^{2}$ Respecting Patient Choices, Austin Health, Melbourne, Victoria

10.1136/bmjspcare-2013-000491.150

Background When confronted with acutely unwell, elderly patients, doctors often have limited knowledge about the patient's wishes for resuscitation. Providing inappropriate resuscitation causes patients to suffer, places unnecessary strain on their families and is a poor use of healthcare resources. Is the general practitioner (GP) well placed to discuss these issues with patients?

Aim To survey the practice and attitudes of GPs and patients to discussing resuscitation and identify strategies to encourage such discussion.

Methods From 18 April 2011 to 26 June 2011 Victorian GPs were surveyed anonymously through GP Divisions of Victoria and patients attending Ararat Medical Clinic aged over 65 were surveyed anonymously.

Results 90 GPs responded.

Identified incentives to discuss resuscitation included: 'knowledge that my patient wanted

\begin{tabular}{lll}
\hline GP Survey answer N=90 & $\begin{array}{l}\text { Frequently or } \\
\text { almost always (\%) }\end{array}$ & $\begin{array}{l}\text { Occasionally or } \\
\text { never }\end{array}$ \\
\hline $\begin{array}{l}\text { I discuss resuscitation with } \\
\text { my patient }\end{array}$ & $24(27 \%)$ & $66(73 \%)$ \\
$\begin{array}{l}\text { I don't because: "lack of } \\
\text { time" }\end{array}$ & $24(36 \%)$ \\
$\begin{array}{l}\text { I don't because: "patients } \\
\text { don't wish to talk about it" }\end{array}$ & $21(32 \%)$ \\
$\begin{array}{l}\text { I don't because: "it should } \\
\text { only be discussed near } \\
\text { death" }\end{array}$ & $18(27 \%)$ \\
$\begin{array}{l}\text { I don't because: "lack of } \\
\text { knowledge/confidence" }\end{array}$ & $2(3 \%)$ \\
\hline
\end{tabular}

discussion' 79\%, 'incorporation into management plan' 71\%, 'discussion guidelines available' 42\%, 'medicare item number' 34\%. Very few felt uncomfortable about the discussion or 'not my duty'.

Of 97 patients, $63 \%$ did not know what a resuscitation order was but $70 \%$ would like their GP to discuss it with them and 84\% would be comfortable talking about it with family.

Discussion Although the majority of GPs do not discuss resuscitation frequently with their patients, for various reasons, there are opportunities, through perceived 'incentives', to improve the discussion rate. The majority of their patients are keen and comfortable to have this discussion.

Conclusion: The majority of GPs believe that it is their responsibility, and the majority of patients that it is their wish, to discuss resuscitation. There are realistic opportunities to increase the discussion rate.

\section{NATIONAL ASSESSMENT OF LIVING WILLS AND DO NOT RESUSCITATE ORDERS}

F L Mirarchi, ${ }^{1}$ E Costello, ${ }^{1}$ J Puller, ${ }^{1}$ T Cooney, ${ }^{1}$ N Kottkamp, ${ }^{2}$ M J Markley ${ }^{3}{ }^{1}$ University of Pittsburgh Medical Center (UPMC) Hamot, Pennsylvania, USA; ${ }^{2}$ MCGuireWoods LLP, Virginia, USA; ${ }^{3}$ M Jane Markley Consulting, LLC, Maryland, USA

10.1136/bmjspcare-2013-000491.151

Background Concern exists that living wills are misinterpreted and may result in compromised patient safety. Aim To determine whether adding code status to a living will improves understanding and treatment decisions.

Methods An Internet survey was conducted of General Surgery and Family, Internal and Emergency Medicine residencies between May and December 2009. The survey posed a fictitious living will with and without additional clarification in the form of code status. An emergent patient care scenario was then presented that included medical history and signs/symptoms. Respondents were asked to assign a code status and choose appropriate intervention. Questions were formatted as dichotomous responses. Correct response rate was based on legal statute. Significance of changes in response due to the addition of either clinical context or code status was assessed by contingency table analysis.

Results 768 faculty and residents at accredited training centres in 34 states responded. At baseline, 22\% denoted 'full code' as the code status for a typical living will and $36 \%$ equated "full care" with a code status DNR. Adding clinical context improved correct responses by $21 \%$. Specifying code status further improved correct interpretation from $28 \%$ to $34 \%$. Treatment decisions were either improved $12-17 \%$ by adding code status ('Full Code,' 'Hospice Care') or worsened 22\% ('DNR'). 
Discussion Further research is required to ensure safety, understanding, and appropriate care to patients.

Conclusion Misunderstanding of advance directives is a nationwide problem. Addition of code status may help to resolve the problem.

\section{ADVANCE CARE PLANNING IN RESIDENTIAL CARE:} 5 YEARS OF CONTINUOUS QUALITY IMPROVEMENT

M Nicholes, ${ }^{1}$ S Billings, ${ }^{1}$ A Perta, ${ }^{2} \mathrm{G}$ Melican ${ }^{2}{ }^{1}$ Alfred Health Advance Care Planning Service, Alfred Health, Victoria, Australia; ${ }^{2}$ Residential Care Services Caulfield Hospital, Alfred Health, Victoria, Australia

\subsection{6/bmjspcare-2013-000491.152}

Aim Until recently Australia has lacked guidelines and practical examples from the field on best practice for implementing Advance Care Planning (ACP) in Residential Care Facilities (RCFs). In 2008 the Victorian Department of Health funded an ACP programme at Alfred Health. This presentation will detail our experience of 5 years of continuous quality improvement in ACP in RCFs.

Methods Alfred Health has three RCFs on site at Caulfield Hospital, which provides care to 120 permanent residents. Over the 5 year time period, initiatives were implemented in an effort to improve ACP processes and outcomes. These included: dedicated ACP staffing time in partnering with staff in RCFs, education and training of staff, development of documents, implementation of systems and procedures, engagement of GP's and the development of an auditing tool to measure change.

Results Prior to the implementation of ACP in 2008, there were no obvious systems in place to support ACP. Documentation of resident end of life care wishes and NFR status were unclear and confusing for staff to follow. The 2012 audit of RCFs at Caulfield Hospital reveal that $89 \%$ of residents participated in ACP and $48 \%$ of residents have clear medical treatment plans which have been completed by the GP.

Conclusion Our experience provides a successful example of how to implement quality improvement in ACP in RCFs over a realistic time frame with limited resources.

\section{DEVELOPING AND IMPLEMENTING A CANCER SPECIFIC MODEL OF ADVANCE CARE PLANNING IN AN AUSTRALIAN CANCER CENTRE: LESSONS FROM PRACTICE}

Angela Baird, ${ }^{1}$ Clare O'Callaghan, ${ }^{1}$ Natasha Michael ${ }^{1}$ Department of Pain and Palliative Care, Peter MacCallum Cancer Centre, Melbourne, Australia

10.1136/bmjspcare-2013-000491.153

Background Despite increasing evidence that Advance Care Planning (ACP) can improve end-of-life care, the majority of cancer patients do not engage in this initiative. A key barrier to this is

Aim To develop a multifaceted programme of service development, education, and research to meet specific organisational needs as well as national and accreditation requirements on ACP in Australia.

Method

Results We will present the successes and challenges of various interventions undertaken including:

1. Electronic enhancement of current Health Information Services to ensure visibility of information and to allow for a more dynamic system to document ongoing conversations

2. Design of ACP documents to reflect the complex nature of decision making in the cancer population

3. Design of appropriate information materials and interventions to allow for healthcare decisions to be documented throughout the cancer trajectory

4. Methods to identify and target learning needs for staff in a cancer centre

5. Policy development and identification of key performance indicators for the cancer populations.

6. Utilisation of a comprehensive research programme to inform and evaluate the above strategies

Conclusion The implementation of a cancer specific model of ACP is a complex intervention requiring the development of an organised clinical microsystem. Challenges which emerge throughout the implementation process will be delineated. Lessons learned will guide ongoing development of the disease specific ACP model in the cancer centre and its feasibility will be examined in a Phase II study of patients with advanced cancer.

\section{PALLIATIVE CARE PRACTICE WITH HIV/AIDS}

Sarah Nandaula ${ }^{1}{ }^{1}$ Hospice Africa Uganda

10.1136/bmjspcare-2013-000491.154

Involvement of people living with HIV/AIDS in the continuum care

Introduction In fulfilling the mission, hospice provides care package that includes holistic assessment counselling, medical care and also provides support in terms of antiretroviral therapy. Home based care, social support, nutrition support, capacity building and advocacy are also given by Hospice Africa

Description Group therapy composed of people living with HIV/AIDS and cancer and the entire gather around and sensitise the rest of patients still in denial land also educate the public on cancer and HIV/AIDS care, support and prevention through dancing, drama, making crafts and sharing life experience. Clients representatives, who are members of centre advisory committees and board of trustees, are involved in care of clients in the community. Palliative care is done by these clients reps in their communities and families are taught by home based teams and 
groups to families. Emotionally they are counselled spiritual support is also given and pain relief given by medical personnel. Clients are empowered to reveal their status by teaching them about disclosure both to family members and to their children. Families are advised to visit their patients frequently and encouraged them every day by telling them how much they have improved.

Lessons Learnt Support structures are useful in proper management of palliative care-the family structures and relatives including counselling are necessary for palliative care. Nutritional support, spiritual support and pain managements very important in palliative care.

Recommendations People living with HIV/AIDS should always include palliative care in their role as caregivers. The best person to understand how it feels like to be very sick is the one who has been through the same situation so care structures should make use of these people.

\section{ADVANCE CARE PLANNING IN JAPANESE NURSING HOMES-USEFULNESS OF END-OF-LIFE CARE TEAM}

M Nishikawa, ${ }^{1}$ Y Yokoe, ${ }^{1}$ N Kubokawa, ${ }^{1}$ K Fukuda, ${ }^{1}$ H Hattori, ${ }^{1}$ H Yong-Jae, ${ }^{1}$ H Miura, ${ }^{1} \mathrm{H}$ Endo, ${ }^{1} \mathrm{~K}$ Nakashima ${ }^{2}{ }^{1}$ National Center for Geriatrics and Gerontology, Japan; ${ }^{2}$ Pallium Hospice, Japan

\subsection{6/bmjspcare-2013-000491.155}

Background Although advance care planning (ACP) in nursing homes is important, the best means of promoting it in Japan remains to be clarified.

Aim The primary aim of this study, which was supported by trained ACP clinicians who are members of end-of-life care teams, was to clarify the usefulness of clinical strategies, such as a lecture about ACP and a multi-occupational interview regarding ACP in nursing homes. The secondary aim was to evaluate the quality of life (QOL) for families of residents who had died in nursing homes as per their wishes.

Methods Out of 108 families of nursing home residents, 59 participated in the lecture. Among the families of residents left the nursing home, we have conducted a multi-occupational interview with 14 families, and investigated the QOL for 13 bereaved families of residents who had died in nursing homes as per their wishes.

Results Out of 14 families of nursing home residents who received a multi-occupational interview, 13 residents died in the nursing home in accordance with the patient' wishes. Intervention by clinical strategies significantly increased the number of residents dying in nursing homes as per their wishes $(p<0.01)$. The QOL of the bereaved was maintained.

Discussion The most important finding was that the residents' wishes were respected.

Conclusion Clinical strategies are more useful in promoting nursing home ACP.
156 PRACTICE OF CONSULTATION FOR ADVANCE DIRECTIVES IN GERMANY: A PILOT STUDY OF CONSULTANTS TRAINED BY A BAVARIAN HOSPICE ACADEMY

S Petri, ${ }^{1} \mathrm{G}$ Marckmann ${ }^{1}{ }^{1}$ Institute of Ethics, History and Theory of Medicine, Ludwig-Maximilians-University of Munich, Germany

10.1136/bmjspcare-2013-000491.156

Background Apart from the pilot project beizeiten begleiten, Advance Care Planning (ACP) programmes are still not widely implemeted in Germany. There is, however, an increasing number of organisations and individuals offering consultation for advance directives (ADs). So far, there is hardly any knowledge about their consulting profile and thereby the quality of ACP in Germany.

Aim To assess the current status of organisation, actual practice and possible improvement of $\mathrm{AD}$-consultation in Germany and thereby the need for structured ACP-programmes.

Methods A pilot study using a written questionnaire (Likert-Scale) completed by 33 consultants participating in a follow up meeting of a Bavarian Hospice Academy.

Results A typical consultation is initiated by the consulted individual himself, takes between 60-90 min and includes one meeting. The age of the consults is predominately between $61-80$ years, they seem to be healthy. $27 \%$ of the participants has no or rarely knowledge about the health status of the consults. 97\% use the same form for AD (Bayerisches Staatsministerium der Justiz), 100\% inform about a proper custody. $91 \%$ suggest to invite a person of trust and report a positive experience of such an integration. They never or rarely exchange with other care providers.

Discussion The results of this pilot study show that these current $\mathrm{AD}$ consultation practices do not yet fully meet the quality criteria of international ACP-programmes (eg, initiatiate conversations, ACP process with several meetings, planning with health care provider, update of plans).

Conclusion It underlines the need for more comprehensive ACP-programmes.

\section{ISSUES ASSOCIATED WITH DELIRIUM SEVERITY AMONG OLDER PATIENTS}

S Rajaram, ${ }^{1}$ H C Chua, S T Lim ${ }^{1}$ Geriatric Nursing Department

\subsection{6/bmjspcare-2013-000491.157}

Aim The goal of this study was to determine whether the issues associated with delirium varied according to the severity of the delirium experienced by the older patients. Delirium among older patients is prevalent and leads to numerous detrimental effects. The negative consequences of delirium are worse among older 
adults with severe delirium compared with patients with mild delirium. There has been no study identifying those factors associated with delirium severity among patients newly admitted to an acute care hospital.

Methodology This is a descriptive study of older patients newly to admitted two geriatric units of Khoo Teck Puat hospital in Singapore $(n=21)$. Upon admission, patients were screened for delirium with the Confusion Assessment Method and severity of delirium symptoms were determined by using the Delirium Index.

Results Of the 21 delirious older patients, 14 had moderate-severe delirium while seven presented mild delirium. In the analyses, a significant positive relationship was observed between the level of prior cognitive impairment and the severity of delirium. Low mini-mental state examination (MMSE) scores the presence of severe illness at the time of hospitalisation and low functional autonomy in instrumental activities of daily living: were significantly associated with moderate-severe delirium. Older patients suffering from mild delirium used significantly more drugs than those with moderate-severe delirium. Results indicated that MMSE score at admission and medication use were the factors most strongly associated with the severity of delirium symptoms.

Discussion This present study indicates that issues associated with moderate-severe delirium are different from those associated with mild delirium. Given the result concerning the role of medication, future studies should evaluate the role of pain management in the context of delirium severity. As moderate-severe delirium is associated with poorer outcomes than is mild delirium, early risk factor identification for moderate-severe delirium by nurses may prove to be of value in preventing further deterioration of those older patients afflicted with delirium

\section{PATIENTS WITH DYSPHASIA: ENCOUNTERS IN TAKING MEDICATION}

S Rajaram, ${ }^{1}$ H C Chua, ${ }^{1}$ X Fu' ${ }^{1}{ }^{1}$ Khoo Teck Puat Hospital

10.1136/bmjspcare-2013-000491.158

Aim This study is an account in discovering the encounters of older people with dysphagia taking their medication.

Background Dysphagia is a common problem notably among the elderly and it affects the digestion of food, fluids and medication. With the number of older people increasing and at present dysphagia has become a major problem in terms of medication administration and therapy.

Method In 2011, we carried out interviews with 11 patients in a restructured hospital in Singapore. These patients had different grades of dysphagia. The interview records were analysed using the Colaizzi technique.

Results Six inter-related themes were distinguished from the data. They are (1) the wide variety and spectrum of dysphagia, (2) Medication formulation, (3) information discussion between patients and health care professionals, (4) circumstances affecting medication observance, (5) approaches used to enhance swallowing and (6) the fundamental purpose of swallowing as eating and drinking.

Conclusion It is essential to ensure that each patient has an individualised medication programme and for patients with dysphagia the formulation of the medicine is as significant as the active ingredients.

\section{QUALITY OF LIFE AMONG END-OF-LIFE FORMER COMMERCIAL PLASMA DONORS INFECTED WITH HIV IN RURAL HENAN, CHINA}

Y Sheng, ${ }^{1} \mathrm{Z} \mathrm{Qiu}_{1}{ }^{2}$ Y He, ${ }^{3}$ Y Zhang ${ }^{4}{ }^{1}$ School of Nursing of Peking Union Medical College; ${ }^{2}$ Department of Society of Beijing University; ${ }^{3}$ Henan Provincial Department of Public Health; ${ }^{4}$ School of Nursing of Tian Jin University

\subsection{6/bmjspcare-2013-000491.159}

Background China has began providing antiretroviral therapy to people living with HIV/AIDS (PLWHA) since 2003.

Aim Purpose of present study was to investigate quality of life and happiness, as well as their needs in hospice care at their end-of-life among HIV-positive people in rural Henan.

Methods One-hundred AIDS patients at their end-of -life were selected from Weishi, Zhenping and Tanghe counties, Henan province of middle China using convenience sampling. WHO Quality of Life for HIV (WHOQOL-HIV) BREF Chinese version was used to measure their quality of life, and Memorial University of Newfoundland Scale of Happiness (MUNSH) was used to measure their subjective welfare. Personal in-depth interview and focus group discussion were used to learn their needs for hospice care at end-of-life of the patients.

Results Overall quality of life was moderate among the patients with an average score of 12.62 and SD of 1.97 , higher in domains of spirituality, religion and personal belief (with an average score of $14.40 \pm 2.96$ ) and psychological domain (13.58 \pm 2.06$)$, and lower in independence $(12.15 \pm 2.15)$ and environment $(12.50$ \pm 3.28 ) domains. Average MUNSH score was 21.00 \pm 6.20 , with moderate range.

Discussion and Conclusion Palliative care model used was beneficial to the patients. In-depth interviews indicated that Henan provincial government's policy of treatment and care for AIDS patients has had a beneficial impact on them at their end-of-life overall, although care component could be improved further by assisting their families as a whole. 
160 MAPPING THE ROLE AND FUNCTION OF CARE ADVISORS WORKING FOR THE MOTOR NEURONE DISEASE ASSOCIATION (WA)

V G Smith ${ }^{1}$ Edith Cowan University, Western Australia

10.1136/bmjspcare-2013-000491.160

Background The role and function of Care Advisors working for the Motor Neurone Disease Association of Western Australia (MNDA[WA]) has been poorly defined or explained. The high turnover of cares has been suggested to be caused by 'terminal burnout' due to the ongoing support carers provide to people living with an aggressive, degenerative neurological condition with death often occurring within months of diagnosis.

Aim The purpose of this research will be to describe the role and function of the MNDA (WA) Care Advisors, find if there are supports for these clinicians which are currently not being met, with the intention of increasing retention of staff.

Methods Qualitative methods will be used including: a literature review of current best practice; observation of interactions with clients; Care Advisor interviews; MND patient interviews about what they see as the role and function of Care Advisors; and review of any workplace guidelines, policies and procedures relating to supportive measures available to the Care Advisors. Thematic analysis will be applied to these data.

Results Results will be presented to the key organisations to underpin development of a supportive framework for Care Advisors. This information will also be submitted to various journals to advance the general world knowledge about MND carers.

Discussion The discussion at this point relates to the anticipated findings and potential benefits of the research. It is anticipated this research may be generalisable to carers for other disease conditions.

Conclusion The research will generate increased knowledge and understanding about the role and function of Care Advisors working with people living with MND.

\section{USING A TEMPLE-BASED EDUCATION PROGRAMME ON BLOOD PRESSURE REDUCTION AMONG BUDDHIST ELDERLY IN RURAL UTTARADIT PROVINCE, NORTHERN THAILAND}

O Stewart, ${ }^{1} \mathrm{~K}$ Yamarat, ${ }^{1}$ E Holroyd ${ }^{2}{ }^{2} \mathrm{~K}$ J Neeser, ${ }^{1}$ S Lertmaharit, ${ }^{1}$ P Phuangnak ${ }^{1}$ College of Public Health Sciences, Chulalongkorn University, Bangkok, Thailand; ${ }^{2}$ School of Health Sciences, RMIT University, Bundoora, Melbourne, Australia; ${ }^{3}$ Boromarajonani College of Nursing, Uttaradit, Thailand

10.1136/bmjspcare-2013-000491.161

Background There has been substantial debate about the contribution of religious practices to alleviating hypertension with some established evidence among
African American. However, Buddhist settings, there has been limited studies of effect of religion on blood pressure reduction.

Aim To determine the effectiveness of a Buddhist temple-based education programme on blood pressure reduction and improving the behavioural changes of exercise, salt intake, intention to visit the physician as well as antihypertensive medications.

Methods A quasi-experimental design was adopted. The study comprised of; (1) the intervention group and (2) the control group. Both groups consisted of 73 persons aged 60 years and above. Data was obtained at baseline and 6 months after the intervention. Temple committee members were trained to be as programme educators. Posters of knowledge about high blood pressure or modifying behaviours on exercise, salt intake and visiting the physician/on antihypertensive medications were placed in strategic locations within the temple environment.

Results Significant reduction in systolic blood pressure was found among participants of the intervention group $(\mathrm{p}<0.001)$. Moreover, systolic blood pressure in the intervention group was found to be significantly lower than that of the control group $(p<0.05)$. In addition, significant behavioural improvement in regards to exercise and salt intake were found among participants of the intervention group compared to the control group (exercise $=\mathrm{p}<0.001$; salt intake $=\mathrm{p}<0.001$ ). However, no significant difference between the intervention and control groups was detected on diastolic blood pressure $(p=0.746)$ and behaviour on visiting the physician/on antihypertensive medications $(p=0.340)$.

Discussion Specific aspect of temple-based education programme can be advocated to an effective way to reduce blood pressure and improve behavioural changes on exercise and salt intake.

Conclusion Nurses should consider including an advocacy for adapting regular Buddhist temple practice in the protocols for hypertensive Buddhist elderly.

\section{KNOWLEDGE AND PERCEPTION ON END-OF-LIFE- CARE, DEATH AND DYING AMONG PALLIATIVE NURSES}

P Subramanian, ${ }^{1} \mathrm{~K}$ Chinna ${ }^{2}{ }^{1}$ Department of Nursing Science, University of Malaya, Kuala Lumpur, Malaysia; ${ }^{2}$ Department of Social and Preventive Medicine University of Malaya, Kuala Lumpur, Malaysia

\subsection{6/bmjspcare-2013-000491.162}

Background Every individual deserved to have good death. Good death is 'peaceful and dignified' without unnecessary suffering of dying. Nursing perspective of 'a good death' is centred in the ability to provide comfort to all involved. Even though many studies have highlighted nurses' perspectives on 
end-of-life-care, this is the first study conducted among Malaysian nurses'.

Aim This study aims to investigate palliative nurses' knowledge and perception on end-of-life-care, death and dying.

Methods A survey was conducted using questionnaire among 177 palliative nurses working in a urban hospital,

Results Majority of the respondents (75\%) had good knowledge on end of life care but have poor perception on end-of-life- care (57\%), experiences towards moment of death (56\%) and experience at the end-of-life (86\%). Only $31(15.5 \%)$ scored good perception on the overall care. The $\chi^{2}$ statistic showed a significant relationship between age and work experience with nurses and perception on end-of-life- care at $\mathrm{p}$ value of $<0.05$.

Discussion Although efforts are being made to improve nurses knowledge on end of life care, practicing nurses still lack of knowledge in providing end-of-life -care and the study findings shows poor perception on end of life care, death and dying. One of the reasons could be due to lack of experience with majority of nurses have less than 1 year experience and below 30 years old.

Conclusion Continued practice development is needed in improving end- of- life- care.

\section{IMPROVING THE ROUTINE UPTAKE OF ADVANCE CARE PLANNING (ACP) DISCUSSIONS IN MANY SETTINGS AS PART OF GSF TRAINING PROGRAMMES IN END OF LIFE CARE}

K Thomas, ${ }^{1,2,3}$ Maggie Stobbart Rowlands, ${ }^{1}$ L Giles, ${ }^{1}$ M Thorn, ${ }^{1}$

C Bloomer ${ }^{4}$ The GSF Centre in End of Life Care, West Midlands, UK;

${ }^{2}$ Birmingham University, Birmingham, UK; ${ }^{3} R C G P$, London, UK; ${ }^{4}$ The Uplands, Shrewsbury, UK

\subsection{6/bmispcare-2013-000491.163}

Background Advance Care Planning is introduced as an integral part of The Gold Standards Framework (GSF) Training Programme in end-of-life care in the UK, in a variety of settings. GSF enables a systematic way to deliver the 'right care, for the right person, in the right place at the right time' and is extensively used across the UK (eg, over 2000 GSF-trained care homes).

There is increased uptake of ACP, but is this the case in different settings?

Aim To demonstrate change in end-of-life care in several settings including routine use of ACP discussions, as part of the GSF Training and Accreditation programmes, These include:-

- Care homes (ACF)

- Primary care

- Acute hospitals

- Domiciliary care

- Community hospitals

To describe increase ACP in GSF care homes.
Methods Evaluation findings following GSF training in End of life care and Accreditation in five settings are described, with illustrations and quantitative and qualitative examples.

Results Increased uptake of ACP discussions was enabled in all settings, with comparative results described. Particularly high results (over 95\%) were from care homes, where the GSF Accreditation standard is that "every resident is offered an ACP discussion."

Discussion Use of training to increase staff confidence, competence and organisation of care can be used extensively across many settings to support better relationships with patients near the end of life, enabling more ACP discussions, leading to better quality end of life care

Conclusion Routine staff training in EOLC and assessment/accreditation of organisations leads to widespread improvements in care.

\section{MEETING THE PRIME MINISTER'S DEMENTIA CHALLENGE: IMPROVING CARE AND INCREASING ACP DISCUSSIONS FOR PEOPLE WITH DEMENTIA FOLLOWING THE GOLD STANDARDS FRAMEWORK (GSF) DEMENTIA CARE TRAINING PROGRAMME}

K Thomas, ${ }^{1} \mathrm{M}$ Stobbart Rowlands, ${ }^{1} \mathrm{~L}$ Giles ${ }^{1}{ }^{1}$ The GSF Centre in End of Life Care, West Midlands, UK

10.1136/bmjspcare-2013-000491.164

Background The UK's Prime Minister's Dementia Challenge highlights the need to improve care for people with dementia. There is growing evidence that hospitalisation can often cause them harm, with increased mortality and morbidity. They can suffer increased disorientation and distress during hospital admissions, with over use of psychotropics and sedatives. However uptake of ACP discussions is often poor.

Aim To improve end-of-life care and reduce hospitalisation for people with dementia through the GSF Dementia Care distance-learning training programme.

The GSF Dementia Care Training interactive programme aims to:

1. Increase awareness of dementia.

2. Improve communication and Advance Care Planning/ Best Interest discussions.

3. Reduce inappropriate hospitalisation, with more dying in their usual place of residence.

4. Improve pain management

Methods The pilot study involving 50 learners from different settings is currently underway, using the GSF Virtual Learning Zone. Certifications is supported by Stafford University.

The evaluation includes recording number of ACPs undertaken, rate of hospitalisation, use of pain assessment tools and illustrative case histories. Evaluations are being analysed, with results available by May 2013 
Results It is hoped that the training programme will show improvements in the areas noted, particularly increased ACP and reduced hospitalisation rates, enabling more to live and die at home.

Discussion These findings are in line with the UK's PM Challenge in dementia.

Conclusion We hope to demonstrate the quantitative and qualitative improvements in care in increased uptake and implementation of ACP discussions in people with dementia.

\section{AN AUDIT OF CURRENT PRACTICE OF DOCUMENTATION AND IDENTIFICATION OF SUBSTITUTE DECISION-MAKERS/PERSONS RESPONSIBLE IN AUSTRALIAN RESIDENTIAL AGED CARE FACILITIES}

M Welz, ${ }^{1}$ W Gee, ${ }^{1}$ B Workman, ${ }^{1,2}$ J Morton ${ }^{3}{ }^{1}$ Rehabilitation and Aged Care Services, Southern Health, Victoria, Australia; ${ }^{2}$ Monash Ageing Research Centre (MONARC), Monash University, Victoria, Australia; ${ }^{3}$ Advance Care Planning Program, Southern Health, Victoria, Australia

\subsection{6/bmjspcare-2013-000491.165}

Background There is little data on the correct identification and documentation of substitute decisionmakers $(\mathrm{SDM})$ or 'persons responsible' $(\mathrm{PR})$ in residential aged care facilities (RACF). Current practice may not be consistent with the Victorian Guardianship and Administration Act (GAA) 1986.

Aim To determine the extent of correct identification and documentation of SDMs or PRs as per GAA in two RACFs in Victoria, Australia.

Methods Retrospective audit of paper and scanned electronic medical records $(\mathrm{n}=88)$.

Admission forms, which include the resident personal details form and the medical admission were examined for identification of next-of-kin (NOK), Power of Attorney-Medical Treatment (POA-MT) or guardian. The complete medical file was then examined to confirm correct identification on the admission forms. VCAT was also contacted where confirmatory documents were not found in medical records.

Results First NOK was more consistently documented than second NOK (75\% vs 33\%).

POA-MT or guardianship with healthcare powers (GHCP) was noted in $~ 15 \%$ of admission forms with only $15.4 \%$ having valid documents available.

In $26.1 \%$, admission forms were unclear; of these, $34.8 \%$ were confirmed to have a POA-MT or GHCP. In 59.1\%, no POA-MT or GHCP was noted; of these, $1.9 \%$ were found to have a POA-MT.

For residents with no confirmed POA-MT or GHCP, the first NOK was a potential PR (as per GAA) in $71.8 \%$. Of these, $49 \%$ were confirmed as the PR.
Discussion/Conclusion Documentation of POA-MT or GHCP is often incomplete or incorrect. A listed NOK is not necessarily the PR. Procedures and forms that use clear, unambiguous terminology must be developed to aid correct identification and documentation of SDMs.

\section{DOCUMENTATION OF ADVANCE END OF LIFE CARE WISHES IN TWO AUSTRALIAN RESIDENTIAL AGED CARE FACILITIES}

M Welz, ${ }^{1}$ W Gee, ${ }^{1}$ B Workman, ${ }^{1,2}$ J Morton ${ }^{3}$ Rehabilitation and Aged Care Services, Southern Health, Victoria, Australia; ${ }^{2}$ Monash Ageing Research Centre (MONARC), Monash University, Victoria, Australia; ${ }^{3}$ Advance Care Planning

Program, Southern Health, Victoria, Australia

10.1136/bmjspcare-2013-000491.166

Background Healthcare professionals often lack awareness of patients' wishes regarding end-of-life care (EOLC). Existing data suggest low utilisation and poor application rates of advance care directives in Australian residential aged care facilities (RACF).

Southern Health RACFs use separate forms to document advance EOLC wishes, namely advance care wishes (ACW), terminal care wishes (TCW) and resuscitation status, however extent and quality of the documented information is unknown.

Aim

1. To audit the documentation rates of EOLC wishes in two low-level RACF in Victoria, Australia.

2. To assess whether documented EOLC wishes are likely to affect medical care in an emergency department (ED) presentation.

Methods Retrospective audit of medical records $(\mathrm{n}=88)$. Assessment of documented EOLC wishes by a consultant physician with expertise in advance care planning.

Results

- ACW including 'particular wishes', 'representatives' wishes' and 'cultural/religious EOL needs' were documented in 78.4, 53.4 and $69.3 \%$ respectively.

- Completion of TCW (form comprising 11 questions regarding EOLC preferences) ranged between 50-65\%.

- Resuscitation management plans available in less than $30 \%$. The majority were for those who did not want resuscitation (93\%).

- Quality of documented EOLC preferences: 66\% assessed as likely to influence decisions in the ED. This includes clear wishes for all active care.

Discussion/Conclusion This audit demonstrates poor documentation of End of Life care wishes in a RACF setting. Healthcare services should prioritise staff and consumer education in this area and improve procedures and forms that provide clear guidelines for the useful documentation of EOL care wishes. 


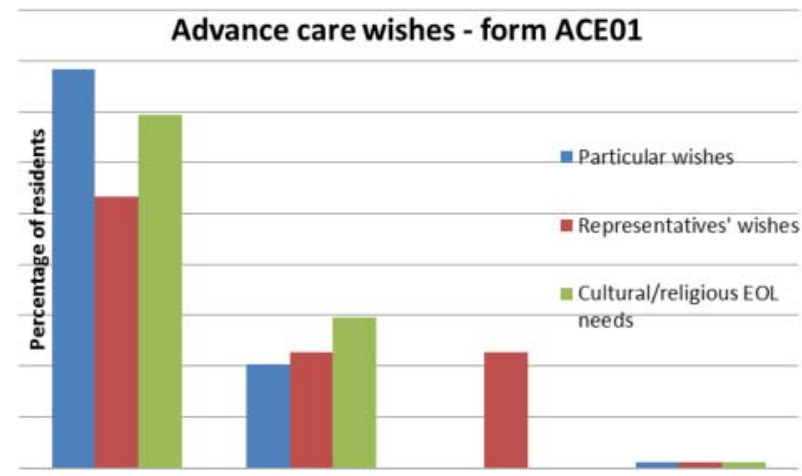

167 ADVANCE CARE PLANNING IN JAPANESE HOSPITALS-USEFULNESS OF END-OF-LIFE CARE TEAM

Y Yokoe, ${ }_{1}^{1}$ M Nishikawa, ${ }^{1}$ N Kubokawa, ${ }_{1}^{1}$ K Fukuda, ${ }^{1}$ H Hattori, ${ }^{1}$ H Yong-Jae, ${ }^{1}$ $\mathrm{H}$ Miura, ${ }^{1} \mathrm{H}$ Endo, ${ }^{1} \mathrm{~K}$ Nakashima ${ }^{2}{ }^{1}$ National Center for Geriatrics and Gerontology, Japan; ${ }^{2}$ Pallium Hospice, Japan

10.1136/bmjspcare-2013-000491.167

Background Although advance care planning (ACP) in hospitals is important, the best means of promoting it in Japan remain to be clarified.

Aim The primary aim of this study was to evaluate the usefulness of end-of-life care teams (EOLCTs) for both cancer and non-cancer patients. The secondary aim was to evaluate the usefulness of narrative life reviews and ACP conducted by full-time EOLCT nurses using qualitative analysis.

Methods We conducted the 'three-pillar strategy for decision making' for the families of 209 patients. There are three large pillars, (1) patient's wishes; (2) family's wishes; and (3) medical judgment. There are also three key pillars in regard to patients' wishes: (1) 'Present': Regardless of the patient's competence/ incompetence, any subtle signs shown by the patient must be noted; (2) 'Past': ACP and narrative life reviews must be checked; and (3) 'Future': The best future interests must be considered. The patient's wish is the most important pillar.

Results Intervention by the three-pillar strategy in EOLCT decision making tended to increase the number of home deaths in accordance with patients' wishes in collaboration with the home care support ward. Narrative life reviews by nurses led to enhancement of ACP.

Discussion The most important finding was that patients' and their families' wishes were respected.
Conclusion The three-pillar strategy used by EOLCT in decision making was useful in enhancing hospitals' ACP.

\section{8 'ADVANCE CARE YARNING' BOOKLET}

L Jones, ${ }^{1}$ S Burgess, ${ }^{2}$ M Seal ${ }^{1}{ }^{1}$ Respecting Patient Choices ${ }^{\circledR}$ Central Adelaide Local Health Network, South Australia; ${ }^{2}$ Aboriginal Health Central Adelaide Local Health Network, South Australia

\subsection{6/bmjspcare-2013-000491.168}

Background Aboriginal Community Health Worker Shane Burgess was employed in 2010 as a Project Officer for the Respecting Patient Choices programme under the Ambulatory and Primary Health Care Directorate. Shane realised that raising awareness throughout the Aboriginal community about the importance of advance care planning requires organisations and staff to have appropriate resources. He hoped such resource might help overcome the great dilemmas around health decisions and moving from country.

Aim To produce a culturally appropriate resource for the Aboriginal Community around advance care planning.

Methods Shane met with Aboriginal Health Workers and made 'well received' progress with the vision for an 'Advance care yarning' booklet.

Consultation with Aboriginal Health Care Workers about the booklet was favourable. The regional media team assisted with the booklet formatting, using a beautiful painting by Aboriginal artist Marlene from Alice Springs. Permission has been obtained for longevity of images used.

Results A Booklet was published with the approval of Aboriginal people and senior Aboriginal Management in Health. Language, artwork and photographs were changed to appeal specifically to the Aboriginal Community

Discussion The RPC Advance Care Planning booklet (Austin Health) was modified to relate to both remote and metropolitan Aboriginal communities. Over 2000 copies have been requested from Aboriginal services and other health services across Australia. The booklet is utilised in current training and development programmes

Conclusion A tool is now provided where there was a gap for engaging and informing Aboriginal people about advanced care planning for Advanced Care Directives.

The booklet has been well received and has been republished. 